\title{
El efecto de la frontera en la recaudación del predial
}

\section{The border effect on property tax revenue}

Jorge Ibarra Salazar*

Lida Sotres Cervantes**

\begin{abstract}
Resumen
Mediante un panel de datos municipales de los estados mexicanos ubicados en la frontera norte, estimamos las diferencias en la recaudación del impuesto predial en cada uno de ellos. Los estimados que se han presentado del efecto frontera en la recaudación del predial hasta ahora no son comparables, ya que han sido obtenidos usando diferentes métodos de estimación y bases de datos. Nuestro objetivo es validar este efecto usando un mismo modelo y método de estimación. Encontramos que, controlando por variables políticas, económicas y fiscales, los municipios de la frontera recaudan 69 pesos más que los no fronterizos.
\end{abstract}

Palabras clave: efecto frontera; impuesto predial; artículo 115 constitucional; instituciones fiscales; frontera norte; México.

* Tecnológico de Monterrey, Departamento de Economía. Dirección: E. Garza Sada 2501 Sur, 64849, Monterrey, Nuevo León, México. Correo electrónico: jaiba rra@itesm.mx_ORCID: https://orcid.org/0000-0002-9581-9099

** Tecnológico de Monterrey, Departamento de Economía. Correo electrónico: lksotres@yahoo.com.mx ORCID: https://orcid.org/0000-0003-3577-7170

Nota de los autores: Este artículo fue realizado durante una estancia académica de Jorge Ibarra Salazar en el Centro México del Baker Institute, Universidad de Rice, en el verano de 2018. Se agradece el auspicio del Consorcio Puentes. Agradecemos también los comentarios de los dictaminadores anónimos. 


\begin{abstract}
In this paper, we use a municipal panel data set of the Mexican states located in the north border. We estimate the differences on property tax revenue on the municipalities of the north border region. Given that the existing estimates have been obtained using different databases and estimation methods, they are not comparable. Our objective is to validate the effect using a consistent model and estimation method. Controlling for political, economic and fiscal variables, we find that border municipalities collect 69 MX pesos above non-border municipalities.
\end{abstract}

Keywords: border effect; property tax; constitutional article 115; fiscal institutions; north border; Mexico.

\title{
Introducción
}

El estudio de los determinantes de la recaudación de ingresos propios de los municipios mexicanos presenta especial relevancia ante el alto grado de dependencia financiera en las transferencias federales y el potencial no explotado de algunas fuentes de ingreso, tal como es el caso del impuesto predial. En efecto, los ingresos propios de los municipios mexicanos, que ascendieron a 79882 millones de pesos en 2015, representan el 20.5\%, en tanto que las transferencias (participaciones y aportaciones federales) aportan el 71.6\% de sus ingresos totales. La importancia de las aportaciones es similar a las participaciones federales (INEGI, 2018a).

Los ingresos por concepto de recaudación del predial constituyen la fuente de ingresos tributarios más importante para los municipios: representan el 6\% de sus ingresos totales, el 30\% de sus ingresos propios, y el $51 \%$ de la recaudación de impuestos. El impuesto predial es también una fuente de ingresos con un potencial no explotado. Países de similar grado de desarrollo al de México recaudan una mayor cuantía relativa de impuesto a la propiedad en comparación con lo que se obtiene en este país. Cifras de la Organización para la Cooperación y el Desarrollo Económicos (OCDE, 2015) indican que México es uno de los países con menor recaudación de impuesto predial como porcentaje de su PIB: sólo $0.3 \%$; mientras que 
Chile recauda $0.9 \%$; Suiza, 1.9\%; Estados Unidos, 2.7\%; y Francia, $4.1 \%$, sólo por mencionar algunos ejemplos. El promedio para los países de la OCDE es de $1.9 \% .{ }^{1}$

A pesar de ello, la literatura que estudia los determinantes de la recaudación del predial en México no es tan extensa como ameritaría su importancia. Se ha estudiado el efecto de las transferencias en la recaudación del predial usando un panel de datos agregados a escala estatal (Unda Gutiérrez y Moreno Jaimes, 2015) y con datos en panel de los municipios (Canavire-Bacarreza y Espinoza, 2015; Broid Krauze, 2010). También Sour (2004; 2008) relaciona el comportamiento de las transferencias no condicionadas y condicionadas con el esfuerzo fiscal $^{2}$ de los municipios mexicanos. La forma en que el entorno político de competencia influye en la recaudación del predial ha sido abordada por Broid Krauze (2010). Considerando los casos de seis municipios urbanos a través de entrevistas semiestructuradas, Unda Gutiérrez (2018) estudia el efecto de las capacidades institucionales y el costo político de ajustar las tablas de valor y las tasas del impuesto sobre la recaudación del predial. También se ha abordado la eficiencia, suficiencia, responsabilidad política, simplicidad administrativa y justicia distributiva del impuesto (Ruelas Ávila, 2015).

Una serie de trabajos de Ibarra Salazar y Sotres Cervantes (2009; 2013 ; 2014; 2015) han abordado los determinantes regionales e institucionales de la recaudación del impuesto predial en los municipios de los estados ubicados en la región frontera norte de México. En estos estudios se han empleado datos que combinan series de tiempo anuales con datos de los municipios de los estados de Sonora (Ibarra Salazar y Sotres Cervantes, 2015), Chihuahua (Ibarra Salazar y Sotres Cervantes, 2014), Coahuila (Ibarra Salazar y Sotres Cervantes, 2013) y Tamaulipas (Ibarra Salazar y Sotres Cervantes, 2009). Su argumento ha sido que las diferencias institucionales en el ámbito fiscal han traído como consecuencia que los municipios fronterizos tengan una mayor recaudación del impuesto predial.

${ }^{1}$ Datos correspondientes a 2015 (OCDE, 2015).

${ }^{2}$ Definido como la razón de ingresos propios a una aproximación del ingreso municipal. 
Por un lado, el mayor dinamismo económico y demográfico de los municipios fronterizos se traduce en un incremento en la demanda de bienes, servicios e infraestructura pública. Por otro, la reforma constitucional de 1999 ha permitido a los municipios modificar sus instituciones fiscales para influir en la recaudación de ingresos. Eso es lo que explica el efecto de la frontera en la recaudación del predial. Se ha estimado que los municipios fronterizos de Tamaulipas recaudaron 2.45 millones de pesos (de 2002) por encima de sus contrapartes no fronterizas (Ibarra Salazar y Sotres Cervantes, 2009); que los municipios fronterizos de Chihuahua recaudaron 24.8 pesos per cápita más que los no fronterizos (Ibarra Salazar y Sotres Cervantes, 2014); que la recaudación per cápita de los municipios fronterizos de Sonora fue mayor en 46.26 pesos a la de los municipios no fronterizos de ese estado (Ibarra Salazar y Sotres Cervantes, 2015); y que en Coahuila el efecto frontera norte representó un diferencial per cápita de 95.65 pesos (Ibarra Salazar y Sotres Cervantes, 2013). Estos estimados, sin embargo, no son comparables, ya que han sido obtenidos usando diferentes métodos de estimación y bases de datos.

Nuestro objetivo en este artículo es contribuir a la literatura que estudia los determinantes de la recaudación del impuesto predial validando el efecto frontera norte. Para cumplir con este objetivo, estimamos y comparamos la cuantía del referido efecto entre los estados fronterizos usando un mismo modelo y método de estimación. Así, calculamos diferentes especificaciones que explican las diferencias de recaudación del impuesto predial usando una base de datos anual (2010-2015), que contiene 225 observaciones de los municipios mexicanos de los estados ubicados en dicha región. En efecto, siguiendo los trabajos que han estimado el efecto frontera en la recaudación del impuesto predial, usamos datos de los estados fronterizos. Como será evidente en la sección de resultados, nuestras estimaciones permiten comparar la recaudación del predial de los municipios fronterizos con los no fronterizos solamente de los estados ubicados en la región mencionada.

El artículo está organizado de la siguiente manera: en la próxima sección se presentan los indicadores sobre el dinamismo económico y demográfico de la región estudiada; en seguida se describen las diferencias en las instituciones en el ámbito fiscal de los estados fronterizos; posteriormente se explica la metodología empleada; la 
siguiente sección contiene los resultados; y la última presenta nuestras conclusiones.

\section{Región frontera norte}

En diversos trabajos se argumenta sobre el dinamismo económico y demográfico que caracteriza a la región frontera norte de México. Los estudios que han abordado ese tema indican que tal dinamismo se explica por: la descentralización industrial de 1985 (Arroyo, 2001); las divergencias regionales causadas por el TLCAN (Chiquiar, 2005); las economías de aglomeración (Deichmann, Lall, Redding y Venables, 2008; Hanson, 2007; Mendoza, 2001); el comercio internacional y la inversión extranjera directa (Mendoza, 2005), entre otros factores. Se resaltan la apertura económica, la inversión extranjera y una mayor integración con la economía norteamericana, como los principales causantes de un intenso crecimiento demográfico y económico en las ciudades fronterizas del norte del país.

La región frontera norte de México está integrada por 37 municipios: tres de Baja California (Mexicali, Tecate y Tijuana); diez de Sonora (Agua Prieta, Altar, Caborca, Naco, Nogales, Puerto Peñasco, San Luis Río Colorado, Santa Cruz, Sáric y Gral. Plutarco Elías Calles); siete de Chihuahua (Ascensión, Guadalupe, Janos, Juárez, Manuel Benavides, Ojinaga y Praxedis G. Guerrero); siete de Coahuila (Acuña, Guerrero, Hidalgo, Jiménez, Nava, Ocampo y Piedras Negras); uno de Nuevo León (Anáhuac); ${ }^{3}$ y nueve de Tamaulipas (Camargo, Guerrero, Gustavo Díaz Ordaz, Matamoros, Mier, Miguel Alemán, Nuevo Laredo, Reynosa y Río Bravo).

La población que se concentra en esta región es de poco más de siete millones de habitantes (Cuadro 1), lo que, de acuerdo a datos de 2015, representa el 6\% de la población total del país (INEGI, 2015). Los municipios más poblados de esta frontera son: Tijuana, B.C. (1.64 millones de habitantes); Juárez, Chih. (1.39 millones); Mexicali, B.C. (988 mil habitantes); Reynosa, Tamps. (646 mil habitantes); y Matamoros, Tamps. (520 mil habitantes). La población en

${ }^{3}$ El municipio de Anáhuac se excluye del grupo debido a que el área colindante con Estados Unidos es muy pequeña, y además no tiene población alguna en la frontera. 
estos cinco municipios representa casi tres cuartas partes $(73.7 \%) \mathrm{del}$ total de la población de los municipios que componen la región frontera norte. Es importante resaltar que Baja California es la entidad de la región que concentra la mayor parte de su población en municipios fronterizos $(82.4 \%)$. Esto significa que cinco de cada seis habitantes aproximadamente residen en un municipio fronterizo. También los estados de Chihuahua y Tamaulipas agrupan una parte considerable de su población en la frontera norte: 41.3 y $51.1 \%$, respectivamente.

\section{Cuadro 1}

Dinámica demográfica de los municipios fronterizos de México

\begin{tabular}{|c|c|c|c|}
\hline \multirow[b]{2}{*}{ Estado / municipio } & \multicolumn{3}{|c|}{ Población } \\
\hline & 2015 & $\begin{array}{c}\% \\
\text { estatal }\end{array}$ & $\begin{array}{c}\Delta \% \\
2000-2015\end{array}$ \\
\hline Baja California & 3315766 & 100.0 & 33.3 \\
\hline Mexicali & 988417 & 29.8 & 29.3 \\
\hline Tecate & 102406 & 3.1 & 31.6 \\
\hline Tijuana & 1641570 & 49.5 & 35.6 \\
\hline Total fronterizos & 2732393 & 82.4 & 33.1 \\
\hline Coahuila & 2954915 & 100.0 & 28.6 \\
\hline Acuña & 147809 & 5.0 & 33.8 \\
\hline Guerrero & 1697 & 0.1 & -17.2 \\
\hline Hidalgo & 1565 & 0.1 & 8.6 \\
\hline Jiménez & 10243 & 0.3 & 5.3 \\
\hline Nava & 30698 & 1.0 & 33.4 \\
\hline Ocampo & 11671 & 0.4 & -3.2 \\
\hline Piedras Negras & 163595 & 5.5 & 27.7 \\
\hline Total fronterizos & 367278 & 12.4 & 28.0 \\
\hline Chihuahua & 3556574 & 100.0 & 16.5 \\
\hline Ascensión & 24966 & 0.7 & 13.8 \\
\hline Guadalupe & 5272 & 0.1 & -47.4 \\
\hline Janos & 10974 & 0.3 & 7.4 \\
\hline Juárez & 1391180 & 39.1 & 14.1 \\
\hline Manuel Benavides & 1403 & 0.0 & -19.6 \\
\hline Ojinaga & 28040 & 0.8 & 15.4 \\
\hline Praxedis G. Guerrero & 5486 & 0.2 & -38.4 \\
\hline Total fronterizos & 1467321 & 41.3 & 13.2 \\
\hline
\end{tabular}




\section{Cuadro 1}

(concluye)

\begin{tabular}{|c|c|c|c|}
\hline \multirow[b]{2}{*}{ Estado / municipio } & \multicolumn{3}{|c|}{ Población } \\
\hline & 2015 & $\begin{array}{c}\% \\
\text { estatal } \\
\end{array}$ & $\begin{array}{c}\Delta \% \\
2000-2015 \\
\end{array}$ \\
\hline Sonora & 2850330 & 100.0 & 28.6 \\
\hline Agua prieta & 82918 & 2.9 & 33.9 \\
\hline Altar & 9578 & 0.3 & 32.1 \\
\hline Caborca & 85631 & 3.0 & 23.2 \\
\hline Naco & 6160 & 0.2 & 14.7 \\
\hline Nogales & 233952 & 8.2 & 46.4 \\
\hline Puerto Peñasco & 62177 & 2.2 & 99.6 \\
\hline S. L. R. Colorado & 192739 & 6.8 & 32.9 \\
\hline Santa Cruz & 1768 & 0.1 & 8.6 \\
\hline Sáric & 1567 & 0.1 & -30.6 \\
\hline Gral. P. Elías Calles & 16931 & 0.6 & 50.1 \\
\hline Total fronterizos & 693421 & 24.3 & 40.0 \\
\hline Tamaulipas & 3441698 & 100.0 & 25.0 \\
\hline Camargo & 15762 & 0.5 & -6.1 \\
\hline Guerrero & 4439 & 0.1 & 1.7 \\
\hline Gustavo Díaz Ordaz & 15398 & 0.4 & -5.2 \\
\hline Matamoros & 520367 & 15.1 & 24.4 \\
\hline Mier & 4326 & 0.1 & -36.3 \\
\hline Miguel Alemán & 27447 & 0.8 & 6.8 \\
\hline Nuevo Laredo & 399431 & 11.6 & 28.5 \\
\hline Reynosa & 646202 & 18.8 & 53.7 \\
\hline Río Bravo & 126887 & 3.7 & 21.7 \\
\hline Total fronterizos & 1760259 & 51.1 & 33.0 \\
\hline Fronterizos & 7020672 & & 28.7 \\
\hline Total nacional & 119530753 & & 22.6 \\
\hline
\end{tabular}

Fuente: INEGI, 2000; 2004; 2014; 2015; 2017.

El dinamismo demográfico de la región durante los últimos quince años también merece especial mención, ya que ha sido mayor al nacional. Mientras que, en conjunto, la población de los municipios fronterizos del norte creció cerca del 30\% entre 2000 y 2015, a nivel nacional el crecimiento poblacional fue de $22.6 \%$ en ese periodo. La 
población municipal de esta frontera registró un crecimiento muy importante en los estados de Sonora (40\%), Baja California (33.1\%), Tamaulipas (33\%) y Coahuila (28\%); todos con tasa de crecimiento mayor a la nacional. Incluso, algunos municipios de estas entidades presentaron un aumento poblacional extraordinario en este lapso de quince años: Puerto Peñasco, Son. (99.6\%); Reynosa, Tamps. (53.7\%); Gral. P. Elías Calles, Son. (50.1\%); Nogales, Son. (46.4\%); y Tijuana, B.C. (35.6\%). Dieciséis municipios fronterizos registraron un crecimiento poblacional mayor que el nacional. En los Cuadros 1, 2 y 3 se muestra información referente a la dinámica demográfica y económica de dichos municipios.

En cuanto a la dinámica económica de la frontera norte, también se observa que ha presentado un crecimiento importante durante los últimos años. El Cuadro 2 muestra cifras de la producción bruta de la industria manufacturera, mientras que el Cuadro 3 expone las remuneraciones pagadas al personal ocupado de la industria maquiladora de exportación en tales municipios.

La producción manufacturera de los municipios fronterizos fue de 411 mil millones de pesos en 2013, lo que significó una participación del $6 \%$ con relación a la producción nacional. Sólo los correspondientes a Baja California aportaron el 40\%. Para revisar la importancia de esta variable económica en el interior de cada estado, se presentan las siguientes cifras: el $94 \%$ de la producción bruta manufacturera de Baja California se concentró en sus municipios fronterizos, mientras que para Chihuahua esta concentración fue del $54 \%$, y para Tamaulipas, del 35\%.

Por su parte, Coahuila destacó con relación al resto de la región debido a su notable dinamismo en las manufacturas. La producción manufacturera de sus municipios fronterizos aumentó 137\% en términos reales durante el periodo 2003-2013, mientras que el crecimiento nacional se ubicó en $63.3 \%$. Tomando en cuenta a los municipios de toda la franja fronteriza, resulta que once registraron un ritmo de crecimiento superior al nacional, y seis tuvieron tasas por encima del 100\% durante el mismo periodo: Ojinaga, Chih. (1123\%); Nava, Coah. (1010\%); Praxedis G. Guerrero, Chih. (156\%); Piedras Negras, Coah. (115\%); Ocampo, Coah. (107\%); y Río Bravo, Tamps. (101\%). 


\section{Cuadro 2}

Dinámica económica de los municipios fronterizos de México: manufacturas

\begin{tabular}{|c|c|c|c|}
\hline \multirow[b]{2}{*}{ Estado / municipio } & \multicolumn{3}{|c|}{ Manufacturas } \\
\hline & $\begin{array}{c}\text { Producción } \\
\text { bruta } 2013 \\
\text { (miles } \$)\end{array}$ & $\begin{array}{c}\% \\
\text { estatal }\end{array}$ & $\begin{array}{c}\Delta \% \\
2003-2013 \\
\end{array}$ \\
\hline Baja California & 174584041 & 100.0 & 59.4 \\
\hline Mexicali & 64212874 & 36.8 & 57.1 \\
\hline Tecate & 8909618 & 5.1 & 77.5 \\
\hline Tijuana & 90802068 & 52.0 & 63.6 \\
\hline Total fronterizos & 163924560 & 93.9 & 61.7 \\
\hline Coahuila & 512703677 & 100.0 & 93.5 \\
\hline Acuña & 6980271 & 1.4 & 18.3 \\
\hline Guerrero & 728 & 0.0 & -99.4 \\
\hline \multicolumn{4}{|l|}{ Hidalgo } \\
\hline Jiménez & 22286 & 0.0 & -32.9 \\
\hline Nava & 11465218 & 2.2 & 1010.3 \\
\hline Ocampo & 2161440 & 0.4 & 107.2 \\
\hline Piedras Negras & 13386951 & 2.6 & 115.3 \\
\hline Total fronterizos & 34016894 & 6.6 & 136.9 \\
\hline Chihuahua & 185881387 & 100.0 & 0.6 \\
\hline Ascensión & 210321 & 0.1 & -85.6 \\
\hline Guadalupe & 6931 & 0.0 & -90.8 \\
\hline Janos & 1243 & 0.0 & -47.8 \\
\hline Juárez & 99047933 & 53.3 & 5.9 \\
\hline \multicolumn{4}{|l|}{ Manuel Benavides } \\
\hline Ojinaga & 1581318 & 0.9 & 1123.4 \\
\hline Praxedis G. Guerrero & 51052 & 0.0 & 156.4 \\
\hline Total fronterizos & 100898798 & 54.3 & 5.9 \\
\hline Sonora & 277842898 & 100.0 & 195.1 \\
\hline Agua Prieta & 1916010 & 0.7 & 17.3 \\
\hline Altar & 5011 & 0.0 & -64.0 \\
\hline Caborca & 534988 & 0.2 & -65.6 \\
\hline Naco & 22118 & 0.0 & -40.1 \\
\hline Nogales & 10495761 & 3.8 & 22.1 \\
\hline
\end{tabular}




\section{Cuadro 2}

(concluye)

\begin{tabular}{|c|c|c|c|}
\hline \multirow[b]{2}{*}{ Estado / municipio } & \multicolumn{3}{|c|}{ Manufacturas } \\
\hline & $\begin{array}{c}\text { Producción } \\
\text { bruta } 2013 \\
\text { (miles } \$)\end{array}$ & $\begin{array}{c}\% \\
\text { estatal }\end{array}$ & $\begin{array}{c}\Delta \% \\
2003-2013\end{array}$ \\
\hline Puerto Peñasco & 318558 & 0.1 & 70.8 \\
\hline S. L. R. Colorado & 2428914 & 0.9 & -30.8 \\
\hline \multicolumn{4}{|l|}{ Santa Cruz } \\
\hline \multicolumn{4}{|l|}{ Sáric } \\
\hline Gral. P. Elías Calles & 17164 & 0.0 & -63.2 \\
\hline Total fronterizos & 15738524 & 5.7 & 1.0 \\
\hline Tamaulipas & 273028104 & 100.0 & 87.7 \\
\hline Camargo & 123210 & 0.0 & -28.4 \\
\hline Guerrero & 2144 & 0.0 & -85.0 \\
\hline Gustavo Díaz Ordaz & 185955 & 0.1 & 77.1 \\
\hline Matamoros & 22594416 & 8.3 & -10.6 \\
\hline Mier & 12839 & 0.0 & -37.0 \\
\hline Miguel Alemán & 44157 & 0.0 & -4.4 \\
\hline Nuevo Laredo & 10619520 & 3.9 & 37.0 \\
\hline Reynosa & 60364854 & 22.1 & 66.4 \\
\hline Río Bravo & 2065920 & 0.8 & 100.9 \\
\hline Total fronterizos & 96013015 & 35.2 & 35.9 \\
\hline Fronterizos & 410591791 & & 38.1 \\
\hline Total nacional & 6745772046 & & 63.3 \\
\hline
\end{tabular}

Fuente: INEGI, 2000; 2004; 2014; 2015; 2017.

Por su ubicación, los municipios de la frontera norte han experimentado un importante avance en el desarrollo de la industria maquiladora de exportación. Mientras que las remuneraciones pagadas al personal ocupado en esta industria crecieron en términos reales a un ritmo de $29.3 \%$ a nivel nacional, en los municipios fronterizos el crecimiento fue mayor: $31.4 \%$ en Baja California, 37\% en Sonora, y 69.1\% en Coahuila. Los que lograron mayor dinamismo (con base en esta variable en particular) en esta industria son: Acuña, Coah. (69.1\%); Nuevo Laredo, Tamps. (39.3\%); Tijuana, B.C. (38.9\%); y Nogales, Son. (37\%). Además del dinamismo, la participación de la industria 
maquiladora de exportación de la zona fronteriza es notable: el 35\% de las remuneraciones pagadas en 2016 a los empleados de esta industria en el país tuvieron lugar en la región frontera norte. Estos sueldos y salarios pagados fueron del orden de 33130 millones de pesos a nivel nacional, y 11556 millones de pesos en los municipios fronterizos.

\section{Cuadro 3}

Dinámica económica de los municipios fronterizos de México: maquiladora de exportación

\begin{tabular}{|c|c|c|c|}
\hline \multirow[b]{2}{*}{ Estado / municipio } & \multicolumn{3}{|c|}{ Maquiladora de exportación } \\
\hline & $\begin{array}{c}\text { Remuneración } \\
2016 \text { (miles \$) }\end{array}$ & $\begin{array}{c}\% \\
\text { estatal }\end{array}$ & $\begin{array}{c}\Delta \% \\
2007-2016\end{array}$ \\
\hline Baja California & 4827589 & 100.0 & 32.9 \\
\hline Mexicali & 1068215 & 22.1 & 16.7 \\
\hline Tecate & 172783 & 3.6 & 5.3 \\
\hline Tijuana & 3295641 & 68.3 & 38.9 \\
\hline Total fronterizos & 4536639 & 94.0 & 31.4 \\
\hline Coahuila & 3048776 & 100.0 & 67.1 \\
\hline Acuña & 434899 & 14.3 & 69.1 \\
\hline \multicolumn{4}{|l|}{ Guerrero } \\
\hline \multicolumn{4}{|l|}{ Hidalgo } \\
\hline \multicolumn{4}{|l|}{ Jiménez } \\
\hline \multicolumn{4}{|l|}{ Nava } \\
\hline \multicolumn{4}{|l|}{ Ocampo } \\
\hline \multicolumn{4}{|l|}{ Piedras Negras } \\
\hline Total fronterizos & 434899 & 14.3 & 69.1 \\
\hline Chihuahua & 4554650 & 100.0 & 27.8 \\
\hline \multicolumn{4}{|l|}{ Ascensión } \\
\hline \multicolumn{4}{|l|}{ Guadalupe } \\
\hline \multicolumn{4}{|l|}{ Janos } \\
\hline Juárez & 3341210 & 73.4 & 28.9 \\
\hline \multicolumn{4}{|l|}{ Manuel Benavides } \\
\hline \multicolumn{4}{|l|}{ Ojinaga } \\
\hline \multicolumn{4}{|l|}{ Praxedis G. Guerrero } \\
\hline Total fronterizos & 3341210 & 73.4 & 28.9 \\
\hline
\end{tabular}




\section{Cuadro 3}

(concluye)

\begin{tabular}{|c|c|c|c|}
\hline \multirow[b]{2}{*}{ Estado / municipio } & \multicolumn{3}{|c|}{ Maquiladora de exportación } \\
\hline & $\begin{array}{c}\text { Remuneración } \\
2016 \text { (miles \$) }\end{array}$ & $\begin{array}{c}\% \\
\text { estatal }\end{array}$ & $\begin{array}{c}\Delta \% \\
2007-2016\end{array}$ \\
\hline Sonora & 1524480 & 100.0 & 17.2 \\
\hline \multicolumn{4}{|l|}{ Agua Prieta } \\
\hline \multicolumn{4}{|l|}{ Altar } \\
\hline \multicolumn{4}{|l|}{ Caborca } \\
\hline \multicolumn{4}{|l|}{ Naco } \\
\hline Nogales & 557918 & 36.6 & 37.0 \\
\hline \multicolumn{4}{|l|}{ Puerto Peñasco } \\
\hline \multicolumn{4}{|l|}{ S. L. R. Colorado } \\
\hline \multicolumn{4}{|l|}{ Santa Cruz } \\
\hline \multicolumn{4}{|l|}{ Sáric } \\
\hline \multicolumn{4}{|l|}{ Gral. P. Elías Calles } \\
\hline Total fronterizos & 557918 & 36.6 & 37.0 \\
\hline Tamaulipas & 2911967 & 100.0 & 22.6 \\
\hline \multicolumn{4}{|l|}{ Camargo } \\
\hline \multicolumn{4}{|l|}{ Guerrero } \\
\hline \multicolumn{4}{|l|}{ Gustavo Díaz Ordaz } \\
\hline Matamoros & 723056 & 24.8 & 13.8 \\
\hline \multicolumn{4}{|l|}{ Mier } \\
\hline \multicolumn{4}{|l|}{ Miguel Alemán } \\
\hline Nuevo Laredo & 481504 & 16.5 & 39.3 \\
\hline Reynosa & 1481065 & 50.9 & 21.7 \\
\hline \multicolumn{4}{|l|}{ Río Bravo } \\
\hline Total fronterizos & 2685625 & 92.2 & 22.2 \\
\hline Fronterizos & 11556291 & & 29.8 \\
\hline Total nacional & 33129807 & & 29.3 \\
\hline
\end{tabular}

Fuente: INEGI, 2000; 2004; 2014; 2015; 2017.

En resumen, para la región de la frontera norte, en los últimos quince años los municipios fronterizos de Baja California, Sonora y Tamaulipas registraron un crecimiento demográfico relevante; mientras que Baja California, Coahuila y Sonora destacaron por su dinamismo económico. 


\section{Instituciones fiscales}

Con el objetivo de otorgarles una mayor autonomía y fortalecer sus finanzas públicas, la reforma al artículo 115 de la Constitución Mexicana de 1999 concedió a los municipios mexicanos más atribuciones en el ámbito fiscal. ${ }^{4}$ Con relación al impuesto predial, se dotó a los municipios de la prerrogativa para proponer a las legislaturas locales tanto las tasas del impuesto como las tablas de valores catastrales. A continuación, se describen las diferentes disposiciones legales que representan el marco institucional en materia del impuesto predial en dichos estados.

Las leyes de hacienda municipal o los códigos financieros municipales de un estado establecen el cobro del impuesto predial, detallando sus elementos y características. En algunos casos, las tasas o tarifas del impuesto se especifican en estas leyes, mientras que, en otros, en la Ley de Ingresos de cada municipio. Los valores catastrales de los predios, que constituyen la base para el cobro del impuesto, se determinan conforme a otros ordenamientos legales (leyes de catastro). Por otra parte, en la mayoría de los casos, la recaudación del predial se incluye como criterio de distribución de las transferencias federales que el estado debe asignar a sus municipios. El Cuadro 4 resume esta información para las cinco entidades fronterizas analizadas.

En Baja California, su Ley de Hacienda Municipal establece el cobro del impuesto predial, el objeto del impuesto, los sujetos obligados, la base del impuesto y las exenciones, entre otros elementos (artículo 75 bis A). La tasa del impuesto, el plazo para pagar y los estímulos se establecen en la Ley de Ingresos de cada municipio. El valor catastral de los predios se determina por lo dispuesto en la Ley del Catastro Inmobiliario del Estado de Baja California (promulgada en 1994), que tiene por objeto "regular la actividad catastral en el territorio del estado" (artículo 1). Entre sus funciones se encuentran integrar el catastro inmobiliario y determinar los valores catastrales de los bienes inmue-

${ }^{4}$ Santana y Sedas (1999) y Santana (2000) describen los aspectos incluidos en la reforma al artículo 115 de 1999. Guillén y Ziccardi (2004, pp. 25-29) reseñan al municipio en las constituciones de México. 
bles del estado (artículo 2). Esta ley establece que el ayuntamiento propondrá los valores unitarios de suelo y construcción, que sirven como base para calcular el valor catastral del predio; el Consejo Municipal del Catastro Inmobiliario ${ }^{5}$ las revisará, y posteriormente se enviarán al Congreso del Estado para su aprobación (artículo 12).

\section{Cuadro 4}

Marco normativo del impuesto predial en los estados fronterizos

\begin{tabular}{|l|l|}
\hline \multicolumn{2}{c}{ Baja California } \\
\hline $\begin{array}{l}\text { Mpios. fijan base y ta- } \\
\text { sas o tarifas de predial }\end{array}$ & $\begin{array}{l}\text { Ley de Hacienda Municipal del Edo. de Baja California; } \\
\text { Ley de Ingresos de cada mpio. }\end{array}$ \\
\hline Valor catastral & $\begin{array}{l}\text { Ley del Catastro Inmobiliario del Edo. de Baja Califor- } \\
\text { nia. }\end{array}$ \\
\hline Agencias involucradas & $\begin{array}{l}\text { Gobernador del edo. (a través de Secretaría de Asenta- } \\
\text { mientos Humanos y Obras Públicas del Edo.); Congreso } \\
\text { del Edo.; consejos municipales de Catastro Inmobiliario; } \\
\text { ayuntamientos; dependencias del Catastro Municipal. }\end{array}$ \\
\hline Agencia catastral & - \\
\hline $\begin{array}{l}\text { Predial para distribuir } \\
\text { transferencias }\end{array}$ & Ley de Coordinación Fiscal del Edo. de Baja California. \\
\hline
\end{tabular}

\section{Coahuila}

\begin{tabular}{|l|l|}
\hline $\begin{array}{l}\text { Mpios. fijan base y ta- } \\
\text { sas o tarifas de predial }\end{array}$ & $\begin{array}{l}\text { Código Financiero para los Mpios. del Edo. de Coahuila; } \\
\text { Ley de Ingresos de cada mpio. }\end{array}$ \\
\hline Valor catastral & $\begin{array}{l}\text { Ley General del Catastro y la Información Territorial para } \\
\text { el Edo. de Coahuila. }\end{array}$ \\
\hline Agencias involucradas & $\begin{array}{l}\text { Congreso del Edo.; Instituto Coahuilense del Catastro y } \\
\text { la Información Territorial; ayuntamientos; unidades ca- } \\
\text { tastrales municipales y direcciones encargadas. }\end{array}$ \\
\hline Agencia catastral & $\begin{array}{l}\text { Instituto Coahuilense del Catastro y la Información Te- } \\
\text { rritorial. }\end{array}$ \\
\hline $\begin{array}{l}\text { Predial para distribuir } \\
\text { transferencias }\end{array}$ & $\begin{array}{l}\text { Ley para la Distribución de Participaciones y Aportacio- } \\
\text { nes Federales a los Mpios. del Edo. de Coahuila. }\end{array}$ \\
\hline
\end{tabular}

\section{Chihuahua}

\begin{tabular}{|l|l|}
\hline $\begin{array}{l}\text { Mpios. fijan base y ta- } \\
\text { sas o tarifas de predial }\end{array}$ & Código Municipal para el Edo. de Chihuahua. \\
\hline Valor catastral & Ley de Catastro del Edo. de Chihuahua. \\
\hline
\end{tabular}

(continúa)

${ }^{5}$ Es el órgano auxiliar de participación social sobre el catastro inmobiliario. 


\section{Cuadro 4}

(concluye)

\begin{tabular}{|l|l|}
\hline Agencias involucradas & $\begin{array}{l}\text { Gobernador del Edo.; presidentes municipales; Congreso } \\
\text { del Edo.; Comité de Apoyo Técnico al Catastro y direc- } \\
\text { ciones encargadas. }\end{array}$ \\
\hline Agencia catastral & - \\
\hline $\begin{array}{l}\text { Predial para distribuir } \\
\text { transferencias }\end{array}$ & - \\
\hline
\end{tabular}

\section{Sonora}

\begin{tabular}{|l|l|}
\hline $\begin{array}{l}\text { Mpios. fijan base y ta- } \\
\text { sas o tarifas de predial }\end{array}$ & $\begin{array}{l}\text { Ley de Hacienda Municipal del Edo. de Sonora; Ley de } \\
\text { Ingresos de cada mpio. }\end{array}$ \\
\hline Valor catastral & Ley Catastral y Registral del Edo. de Sonora. \\
\hline Agencias involucradas & $\begin{array}{l}\text { Ayuntamientos; Instituto Catastral y Registral del Edo. de } \\
\text { Sonora; Consejos Catastrales Municipales. }\end{array}$ \\
\hline Agencia catastral & Instituto Catastral y Registral del Edo. de Sonora. \\
\hline $\begin{array}{l}\text { Predial para distribuir } \\
\text { transferencias }\end{array}$ & $\begin{array}{l}\text { Decreto que Establece los Factores de Distribución de } \\
\text { Participaciones Federales a los Mpios. del Edo. de So- } \\
\text { nora. }\end{array}$ \\
\hline
\end{tabular}

\section{Tamaulipas}

\begin{tabular}{|l|l|}
\hline $\begin{array}{l}\text { Mpios. fijan base y ta- } \\
\text { sas o tarifas de predial }\end{array}$ & $\begin{array}{l}\text { Código Municipal para el Edo. de Tamaulipas; Ley de In- } \\
\text { gresos de cada mpio. }\end{array}$ \\
\hline Valor catastral & Ley de Catastro para el Edo. de Tamaulipas. \\
\hline Agencias involucradas & $\begin{array}{l}\text { Gobernador del Edo.; Secretaría de Finanzas; Institu- } \\
\text { to Registral y Catastral del Edo. de Tamaulipas; ayunta- } \\
\text { mientos; Junta Municipal de Catastro y áreas encargadas. }\end{array}$ \\
\hline Agencia catastral & Instituto Registral y Catastral del Edo. de Tamaulipas. \\
\hline $\begin{array}{l}\text { Predial para distribuir } \\
\text { transferencias }\end{array}$ & Ley de Coordinación Fiscal del Edo. de Tamaulipas. \\
\hline
\end{tabular}

Fuente: Elaboración propia.

En cuanto a las participaciones federales a los municipios, la Ley de Coordinación Fiscal del Estado de Baja California establece que el $70 \%$ de éstas se distribuirá en proporción directa a la suma de la recaudación del impuesto predial y de los derechos por servicio de consumo de agua potable que registre cada municipio (artículo 4). Además, del monto correspondiente a los municipios por concepto de la recaudación por cuotas por la venta final al público de gasolina y diésel, el estado distribuirá el $20 \%$ en proporción directa a la recaudación del impuesto predial de cada municipio (artículo 4 bis). 
En Coahuila, es el Código Financiero para los Municipios del Estado de Coahuila de Zaragoza el que establece el cobro del impuesto predial, especificando su objeto, los sujetos obligados, la base del impuesto, el plazo para pagar y las exenciones, entre otros asuntos (del artículo 33 al 48). Las tasas y tarifas para el cálculo del impuesto, así como los incentivos y estímulos, se establecen en la Ley de Ingresos de cada municipio. Los valores catastrales se determinan por lo dispuesto en la Ley General del Catastro y la Información Territorial para el Estado de Coahuila de Zaragoza (promulgada en 1999). Esta ley tiene por objeto “organizar y regir la función catastral en el Estado de Coahuila de Zaragoza, así como establecer las bases para el control y valoración de la propiedad inmobiliaria" (artículo 1). Coahuila cuenta con el Instituto Coahuilense del Catastro y la Información Territorial, que es "la autoridad encargada de todo lo relacionado con la planeación, rectoría, vigilancia y subsidiariedad administrativa en materia de catastro en el estado" (artículo 14). El Instituto tiene por objeto: emitir políticas y normas técnicas para la función catastral en el estado, uniformar la normatividad de los municipios en materia catastral, llevar a cabo investigación técnica y tecnológica de métodos y técnicas de valuación catastral, elaborar y actualizar la cartografía y planos catastrales, formular los proyectos de tablas de valores unitarios de suelo y construcción junto con la Unidad Catastral Municipal, ${ }^{6}$ prestar servicios periciales y asistencia técnica a los municipios, entre otros (artículo 10). Esta ley establece que la Unidad Catastral Municipal y el instituto mencionado propondrán las tablas de valores unitarios de suelo y construcción, base para determinar los valores catastrales, mientras que el ayuntamiento realizará su revisión y, a su vez, las remitirá al Congreso del Estado para su aprobación (artículos 10, 11 y 12).

Para el reparto de las participaciones federales, la Ley para la Distribución de Participaciones y Aportaciones Federales a los Municipios del Estado de Coahuila de Zaragoza establece que una parte

${ }^{6}$ Es el área del ayuntamiento integrada por personal técnico y administrativo que tiene como funciones elaborar los proyectos de las tablas de valores unitarios de suelo y construcción, proponer los valores catastrales, describir, clasificar y valuar la propiedad raíz del municipio, entre otras. 
(casi la mitad) del 86.5\% del Fondo General de Participaciones correspondientes a los municipios se distribuya en proporción directa a su recaudación de impuesto predial y derechos por el servicio de agua. Otra pequeña parte $(5 \%)$ de este fondo se distribuirá a los municipios tomando en cuenta el incremento en la recaudación del impuesto predial (artículo 4). La fórmula para el reparto del Fondo de Fomento Municipal también incluye como criterios tanto el monto de la recaudación del impuesto predial como el crecimiento de ésta (artículo 6).

Chihuahua, por su parte, establece el cobro del impuesto predial en el Código Municipal para el Estado de Chihuahua, donde se especifican el objeto del gravamen, los sujetos obligados, la base del impuesto, las tasas, las exenciones y el plazo para el pago del impuesto (del artículo 145 al 154). El valor catastral se determina por la Ley de Catastro del Estado de Chihuahua (promulgada en 1995), que regula la actividad catastral en la entidad (artículo 1). Esta ley tiene como objeto: establecer normas para la realización de las actividades catastrales en el estado para la integración y actualización de los registros de los predios; promover la descentralización de las funciones catastrales hacia los municipios; y determinar los procedimientos de valuación de los predios, entre otros (artículo 2). De acuerdo a esta ley, la autoridad catastral municipal formulará y propondrá al ayuntamiento las tablas de valores unitarios para suelo y construcción, que a su vez serán enviadas al Congreso del Estado para su aprobación (artículo 6).

Con relación a la distribución de las participaciones y aportaciones federales a los municipios, Chihuahua distribuye las transferencias de acuerdo a la población, el importe de su presupuesto de egresos, el gasto público municipal por habitante y el número de localidades (artículo 315 del Código Fiscal del Estado de Chihuahua).

En Sonora, la Ley de Hacienda Municipal constituye el marco normativo del impuesto predial. Esa ley define el objeto del impuesto, los sujetos obligados, la base del impuesto y el plazo para el pago (del artículo 51 al 69). Las tarifas son fijadas por los ayuntamientos en las Leyes de Ingresos de cada municipio. El valor catastral se determina por lo dispuesto en la Ley Catastral y Registral del Estado de Sonora (promulgada en 1992), cuyo objeto es establecer normas para 
la realización de las funciones catastral y registral, para la formulación del registro y valuación de los bienes inmuebles en el estado, y para la integración del Sistema Estatal de Información Catastral, entre otros (artículo 1). El Instituto Catastral y Registral del Estado de Sonora es un órgano administrativo desconcentrado con autonomía técnica, operativa y presupuestal, y subordinado a la Secretaría de Finanzas (artículo 39). Entre sus funciones se encuentran: otorgar apoyo técnico en materia de catastro, emitir normas para la realización de las funciones catastrales, uniformar la normatividad de los municipios en esta materia, integrar el inventario inmobiliario, valuar los predios cuando exista convenio con el municipio, y realizar investigación científica y tecnológica, entre otras (artículo 40). La Ley Catastral y Registral también establece que los ayuntamientos, con el apoyo del Instituto cuando sea requerido, propondrán los valores unitarios de suelo y construcción, que serán enviados al Congreso del Estado para su aprobación (artículo 10). Los ayuntamientos también pueden crear los Consejos Catastrales Municipales como órganos de consulta y apoyo que, entre otras atribuciones, pueden opinar sobre las tablas de valores unitarios de los terrenos y construcciones.

De acuerdo al Decreto que Establece los Factores de Distribución de Participaciones Federales a los Municipios del Estado de Sonora, entre los criterios que la entidad emplea para distribuir las participaciones federales a sus municipios se encuentra el incremento en la recaudación del impuesto predial, así como de los derechos por servicios de agua potable y alcantarillado, y del impuesto sobre la tenencia o uso de vehículos (artículo 3).

Finalmente, Tamaulipas establece el cobro del impuesto predial en el Código Municipal para el Estado de Tamaulipas. Se especifica el objeto del impuesto, los sujetos obligados, la base, el plazo del pago, las exenciones, entre otros asuntos (del artículo 104 al 123). Las tasas se fijan en las Leyes de Ingresos Municipales. El valor catastral se determina conforme a lo establecido en la Ley de Catastro para el Estado de Tamaulipas (promulgada en 2001), cuyo objeto es integrar el catastro inmobiliario, definir las autoridades catastrales y sus facultades, fijar las obligaciones en materia de catastro, definir las normas y procesos técnicos de las actividades catastrales, valuar los bienes inmuebles de los municipios, integrar y actualizar 
el padrón de los predios, entre otros (artículo 1). La entidad cuenta con el Instituto Registral y Catastral del Estado de Tamaulipas, el cual deberá planificar, controlar y dirigir las actividades catastrales de la entidad (artículo 13). El ayuntamiento propondrá las tablas de valores unitarios de suelo y construcción (con apoyo del Instituto cuando exista un convenio de apoyo técnico catastral), y las enviará al Congreso del Estado para su aprobación (artículos 13 y 15). El ayuntamiento también podrá promover la consulta y la participación ciudadana relacionadas con las tablas de valores unitarios de suelo y construcción.

El artículo 7 de la Ley de Coordinación Fiscal del Estado de Tamaulipas establece que la entidad distribuirá entre sus municipios una parte del Fondo Estatal de Participaciones de acuerdo a una fórmula que toma en cuenta la recaudación del impuesto predial del municipio. El reparto de otro fondo federal, el Fondo de Fiscalización, toma en cuenta el incremento en la recaudación del impuesto predial, así como en los derechos de agua (artículo 9).

Este marco normativo en el ámbito fiscal implica diferencias institucionales entre los estados y municipios considerados en este estudio. Para ilustrarlo, hemos resumido algunas de las reglas y procedimientos en tres municipios de cada una de las entidades fronterizas consideradas en el artículo.

En Chihuahua, el marco normativo estatal determina la tasa que deben aplicar los municipios a la base del impuesto, mientras que cada municipio determina, entre otros, los descuentos por pronto pago y los criterios para reducir el impuesto a los proyectos de inversión, a ciertos sectores económicos y a desarrollos inmobiliarios (Cuadro 5).

En Coahuila, la normativa fiscal estatal indica que las tarifas del impuesto son definidas en las leyes municipales. En el Cuadro 6, y para efectos de ilustración, se pueden apreciar las diferencias en las tarifas, los criterios para reducir el impuesto a sectores económicos y los proyectos de inversión de Saltillo, Piedras Negras y Torreón.

Tal criterio también aparece en la legislación estatal de Sonora. Como se aprecia en el Cuadro 7, en el municipio de Hermosillo la tarifa del impuesto es de nueve al millar, en tanto que en Cajeme es de 1.345 al millar, y en Nogales es 1\% sobre el valor catastral. Nótese 
que los descuentos por pronto pago del impuesto son también distintos en esos tres casos. A pesar de ello, el marco normativo a escala estatal de Sonora marca los descuentos a grupos vulnerables que deben aplicarse en todos los municipios.

\section{Cuadro 5}

\section{Marco normativo del impuesto predial} de los municipios de Chihuahua, 2015

\begin{tabular}{|c|c|}
\hline \multicolumn{2}{|r|}{ Chihuahua } \\
\hline Ley municipal & Ley de Ingresos del Mpio. de Chihuahua. \\
\hline $\begin{array}{l}\text { Contribuciones } \\
\text { extraordinarias }\end{array}$ & $\begin{array}{l}\text { 3\% (fideicomiso Expo-Chihuahua) y 4\% (universidades) } \\
\text { sobre predial y cuota fija de } \$ 5 \text { (art. 7). }\end{array}$ \\
\hline Pronto pago & $12 \%$ en enero, $8 \%$ en feb. y $4 \%$ en mzo. (art. 8 ). \\
\hline Grupos vulnerables & $\begin{array}{l}50 \% \text { para pensionados, jubilados mayores de } 60 \text { años y } \\
\text { personas con discapacidad total permanente; } 25 \% \text { si una } \\
\text { persona con discapacidad habita la casa de su ascendente } \\
\text { o descendente en línea recta; } 50 \% \text { a madres o padres sol- } \\
\text { teros, divorciados o viudos con hijos menores de edad y } \\
\text { escasos recursos (art. 10). }\end{array}$ \\
\hline Históricos & $\begin{array}{l}\text { 50\% para inmuebles catalogados o declarados como mo- } \\
\text { numentos históricos (art. 13). }\end{array}$ \\
\hline Área verde & $\begin{array}{l}20 \% \text { para predios urbanos de } 5000 \mathrm{~m}^{2} \text { o más, destinados } \\
\text { o habilitados en } 80 \% \text { para área verde, jardineada o arbo- } \\
\text { lada (art. 13). }\end{array}$ \\
\hline Proyecto inversión & $\begin{array}{l}\text { Generación de empleos, nivel salarial de empleos, monto } \\
\text { de inversión, procedencia de insumos y compra a provee- } \\
\text { dores locales, hasta } 50 \% \text { (art. 22). }\end{array}$ \\
\hline Sectores económicos & $\begin{array}{l}100 \% \text { para personas físicas o morales que realicen activi- } \\
\text { dades industriales, aeroespaciales, hospitales, tecnologías } \\
\text { de la información, agroindustriales (art. 23). }\end{array}$ \\
\hline Desarrollos & $\begin{array}{l}100 \% \text { para personas físicas y morales que desarrollen } \\
\text { fraccionamientos, conjuntos urbanos o edificaciones que } \\
\text { promuevan el desarrollo urbano ordenado y sustentable } \\
\text { que incida en la consolidación y compactación de la ciu- } \\
\text { dad (arts. } 34 \text { y } 35 \text { ). }\end{array}$ \\
\hline Tarifa & $\begin{array}{l}\text { Predios suburbanos } 3 \text { al millar sobre valor catastral. Im- } \\
\text { puesto neto a pagar no será inf. al equivalente a } 2 \text { días de } \\
\text { SMG (anexo Periódico Oficial, p. 19). }\end{array}$ \\
\hline
\end{tabular}

(continúa) 


\section{Cuadro 5}

(continúa)

\begin{tabular}{|l|l|}
\hline \multicolumn{2}{|c}{ Juárez } \\
\hline Ley municipal & Ley de Ingresos del Mpio. de Juárez. \\
\hline $\begin{array}{l}\text { Contribuciones } \\
\text { extraordinarias }\end{array}$ & $\begin{array}{l}\text { 3\% (Fideicomiso Paso del Norte) y 4\% (universidades) } \\
\text { sobre predial. 20\% del impuesto para predios urbanos no } \\
\text { edificados o cuya construcción tenga valor inf. a 10\% del } \\
\text { valor del terreno (art. 6). }\end{array}$ \\
\hline Pronto pago & $\begin{array}{l}12 \% \text { en enero y 7\% en feb. Además, a quienes no tengan } \\
\text { adeudos de años anteriores, 3\% en enero y feb. (art. 8). }\end{array}$ \\
\hline Grupos vulnerables & $\begin{array}{l}50 \% \text { a personas mayores de 60 años; 50\% a personas con } \\
\text { discapacidad o que tengan patria potestad de discapaci- } \\
\text { tados (art. 8). }\end{array}$ \\
\hline Históricos & $\begin{array}{l}100 \% \text { a propietarios de inmuebles declarados patrimonio } \\
\text { cultural en el mpio. (art. 8). }\end{array}$ \\
\hline Área verde & - \\
\hline Proyecto inversión & $\begin{array}{l}\text { Personas físicas o morales que realicen inversión inmo- } \\
\text { biliaria entre 20 y 40 mdp, 15\%; o más de 40 mdp, 20\% } \\
\text { (art. 8). }\end{array}$ \\
\hline Sectores económicos & - \\
\hline Desarrollos & - \\
\hline Tarifa & - \\
\hline
\end{tabular}

Delicias

\begin{tabular}{|l|l|}
\hline Ley municipal & Ley de Ingresos del Mpio. de Delicias. \\
\hline $\begin{array}{l}\text { Contribuciones } \\
\text { extraordinarias }\end{array}$ & $\begin{array}{l}\text { Universitario sobretasa de 4\% al monto del impuesto pre- } \\
\text { dial (art. 20). }\end{array}$ \\
\hline Pronto pago & $\begin{array}{l}15 \% \text { en enero y 10\% en feb. si se paga en forma antici- } \\
\text { pada cuando menos 3 bimestres. 10\% (5\%) si el primer } \\
\text { pago se hizo en enero (feb.) y el resto lo cubre antes de } \\
\text { junio (art. 9). Impuesto predial rústico 50\% por pago en } \\
\text { enero y feb. (art. 13). }\end{array}$ \\
\hline Grupos vulnerables & $\begin{array}{l}\text { 50\% a pensionados, jubilados y mayores a 60 años (art. } \\
10) ; 50 \% \text { a personas con discapacidad permanente o que } \\
\text { tengan a cónyuge o hijo con discapacidad (art. 11); 50\% a } \\
\text { madres o padres solteros en situación precaria y que sean } \\
\text { jefes de familia (art.12); 50\% a adultos que cursen edu- } \\
\text { cación básica en el Instituto Chihuahuense de Educación } \\
\text { para Adultos (art. 14). }\end{array}$ \\
\hline Históricos & - \\
\hline Área verde & - \\
\hline
\end{tabular}




\section{Cuadro 5}

(concluye)

\begin{tabular}{|l|l|}
\hline Proyecto inversión & $\begin{array}{l}\text { Personas físicas y morales que generen nueva inversión } \\
\text { y dependiendo de los empleos generados, monto de in- } \\
\text { versión, compra a proveedores locales, oportunidades de } \\
\text { empleo para adultos mayores y/o personas con discapa- } \\
\text { cidad, pueden obtener estímulo de } 100 \% \text { del predial en } \\
2015 \text { y 50\% en 2016. Dependiendo de esos criterios se } \\
\text { pueden obtener estímulos estatutarios respecto al predial } \\
\text { (arts. 22 y 23). }\end{array}$ \\
\hline Sectores económicos & - \\
\hline Desarrollos & El impuesto mínimo anual para inmuebles urbanos y rús- \\
\hline Tarifa & ticos es de \$293 (art. 8). \\
\hline
\end{tabular}

Fuente: Leyes de Ingresos Municipales, http://www.chihuahua.gob.mx/hacienda/leyesmpios-2015

\section{Cuadro 6}

\section{Marco normativo del impuesto predial} de los municipios de Coahuila, 2015

\begin{tabular}{|l|l|}
\hline Ley estatal & $\begin{array}{l}\text { Código Financiero para los Mpios. del Edo. de Coahuila } \\
\text { de Zaragoza. }\end{array}$ \\
\hline Base & $\begin{array}{l}\text { Valor catastral de los predios. Cuando no exista, la base será } \\
\text { el valor de la producción anual comercializada (art. 35). }\end{array}$ \\
\hline Tarifa & La que establezca la Ley de Ingresos Municipal (art. 36). \\
\hline Exenciones & $\begin{array}{l}\text { Bienes del dominio público de la federación, de los edos. o } \\
\text { los mpios. (art. 37). }\end{array}$ \\
\hline
\end{tabular}

\section{Saltillo}

\begin{tabular}{|l|l|}
\hline Ley municipal & Ley de Ingresos del Mpio. de Saltillo. \\
\hline $\begin{array}{l}\text { Contribuciones } \\
\text { extraordinarias }\end{array}$ & - \\
\hline Pronto pago & $15 \%$ en enero, $10 \%$ en feb. y $5 \%$ en mzo. (art. 2). \\
\hline Grupos vulnerables & $\begin{array}{l}50 \% \text { a pensionados, jubilados, adultos mayores y personas } \\
\text { con discapacidad permanente. }\end{array}$ \\
\hline Proyecto inversión & $\begin{array}{l}\text { Empresas de nueva creación y ya existentes que generen } \\
\text { nuevos empleos directos, incentivo de } 15 \text { a 100\% (art. } 2 \text { ). }\end{array}$ \\
\hline Sectores económicos & $\begin{array}{l}50 \% \text { a instituciones de beneficencia e instituciones educa- } \\
\text { tivas no públicas con autorización o reconocimiento de va- } \\
\text { lidez (art. 2). }\end{array}$ \\
\hline
\end{tabular}




\section{Cuadro 6}

(continúa)

\begin{tabular}{|c|c|}
\hline Desarrollos & $\begin{array}{l}\text { Incentivo a predios con licencia de fraccionamiento auto- } \\
\text { rizada por el mpio. que se encuentre en vías de desarrollo } \\
\text { pagando } 30 \% \text { del predial correspondiente al valor consi- } \\
\text { derado como predio ya fraccionado y desarrollado (art. } 2 \text { ). }\end{array}$ \\
\hline $\begin{array}{l}\text { Tarifa base = valor } \\
\text { catastral }\end{array}$ & $\begin{array}{l}\text { I. Urbanos con edificación, } 1.5 \text { al millar. } \\
\text { II. Urbanos sin edificaciones, } 1.8 \text { al millar. } \\
\text { III. Urbanos sin edificaciones contiguos a los bulevares, } \\
\text { avs. principales, fuera de uso hab., } 2.1 \text { al millar. } \\
\text { IV. Rústicos y de extracción ejidal ya titulados, } 5 \text { al millar. } \\
V . \text { Industriales con edificación, } 1.5 \text { al millar. } \\
\text { VI. Industriales sin edificaciones, } 1.8 \text { al millar. } \\
\text { VII. Comerciales con edificación, } 1.5 \text { al millar } \\
\text { VIII.Comerciales sin edificaciones, } 1.8 \text { al millar (art. 2). }\end{array}$ \\
\hline Límite & $\begin{array}{l}\text { En ningún caso el monto del predial será inf. a \$24 por bi- } \\
\text { mestre (\$144 anual) (art. 2). }\end{array}$ \\
\hline
\end{tabular}

Piedras Negras

\begin{tabular}{|c|c|}
\hline Ley municipal & Ley de Ingresos del Mpio. de Piedras Negras. \\
\hline $\begin{array}{l}\text { Contribuciones } \\
\text { extraordinarias }\end{array}$ & - \\
\hline Pronto pago & $15 \%$ en enero, $10 \%$ en feb. y $5 \%$ en mzo. (art. 2 ). \\
\hline Grupos vulnerables & $\begin{array}{l}50 \% \text { a pensionados, jubilados, adultos mayores y personas } \\
\text { con capacidades diferentes (art. } 2 \text { ). }\end{array}$ \\
\hline Proyecto inversión & $\begin{array}{l}\text { Empresas que establezcan nuevos centros de trabajo, así } \\
\text { como empresas nuevas tendrán incentivo de } 15 \text { a } 90 \% \text { en } \\
\text { función del núm. de empleos directos generados (art. 2). }\end{array}$ \\
\hline Sectores económicos & - \\
\hline Desarrollos & - \\
\hline $\begin{array}{l}\text { Tarifa } \\
\text { base }=\text { valor catastral }\end{array}$ & $\begin{array}{l}\text { I. } 0 \text { a } 60000 \text { : edificado uso hab., } \$ 102 \text {, y no hab., } \$ 134 \text {. } \\
\text { 64; no edificado con barda, } \$ 120 \text {, y sin barda, } \$ 189 \text {. } \\
\text { II. } 60000 \text { a } 90000 \text { : edificado uso habitacional, } \$ 142.2 \text {, y } \\
\text { no habitacional, } \$ 189 \text {; no edificado con barda, } \$ 180 \text {, y } \\
\text { sin barda, } \$ 283.5 \text {. } \\
\text { III. } 90000 \text { a } 135000 \text { : edificado uso habitacional, } \$ 213.30 \text {; } \\
\text { no habitacional, } \$ 283.50 \text {; no edificado con barda, } \$ 270 \text {, } \\
\text { y sin barda, } \$ 425.25 \text {. } \\
\text { IV. } 135000 \text { en adelante: edificado uso habitacional, } 1.52 \text { al } \\
\text { millar; no habitacional, } 2.10 \text { al millar; no edificado con } \\
\text { barda, } 2.10 \text { al millar, y sin barda, } 3.15 \text { al millar (art. } 2 \text { ). }\end{array}$ \\
\hline Límite & $\begin{array}{l}\text { En ningún caso el predial urbano o rústico será inf. a \$17 } \\
\text { por bimestre (art. } 2 \text { ). }\end{array}$ \\
\hline
\end{tabular}




\section{Cuadro 6}

(concluye)

\begin{tabular}{|c|c|}
\hline \multicolumn{2}{|r|}{ Torreón } \\
\hline Ley municipal & Ley de Ingresos del Mpio. de Torreón. \\
\hline $\begin{array}{l}\text { Contribuciones } \\
\text { extraordinarias }\end{array}$ & $\begin{array}{l}\text { Contribuciones, entre otras, que tienen como base el pago } \\
\text { de predial: por mantenimiento y conservación del centro } \\
\text { histórico (art. 12), mantenimiento e instalación de señala- } \\
\text { mientos viales, sistema de protección civil municipal, De- } \\
\text { sarrollo Integral de la Familia (art. 13). }\end{array}$ \\
\hline Pronto pago & $\begin{array}{l}20 \% \text { y seguro contra robo e incendio en enero, } 15 \% \text { en feb. } \\
\text { y } 10 \% \text { en mzo. (art. } 72 \text { ). }\end{array}$ \\
\hline Grupos vulnerables & $\begin{array}{l}50 \% \text { a pensionados, jubilados, adultos mayores o con dis- } \\
\text { capacidad (art. } 72) \text {. }\end{array}$ \\
\hline Proyecto inversión & $\begin{array}{l}\text { Empresas de nueva creación y existentes, incentivo de } 20 \\
\text { a } 70 \% \text { en función de empleos directos creados (art. 73). }\end{array}$ \\
\hline Sectores económicos & $\begin{array}{l}\text { Instituciones educativas no públicas con autorización o re- } \\
\text { conocimiento de validez oficial, } 1 \text { al millar del valor catas- } \\
\text { tral. Incentivo de } 100 \% \text { a cementerios (art. } 72 \text { ) y de } 25 \% \text { a } \\
\text { propietarios de inmuebles de uso comercial en centro his- } \\
\text { tórico (art. 74). }\end{array}$ \\
\hline Desarrollos & - \\
\hline $\begin{array}{l}\text { Tarifa } \\
\text { base }=\text { valor catastral }\end{array}$ & $\begin{array}{l}\text { I. } 0.01 \text { a } 40000 \text { : cuota fija } \$ 84.56 \text { y tasa } 0.5 \text { al millar sobre } \\
\text { excedente del límite inf. } \\
\text { II. } 40000 \text { a } 80000 \text { : cuota fija } \$ 107.90 \text { y tasa } 1.00 \text { al millar } \\
\text { sobre excedente del límite inf. } \\
\text { III. } 80000 \text { a } 120000 \text { : cuota fija } \$ 154.55 \text { y tasa } 1.5 \text { al millar } \\
\text { sobre excedente del límite inf. } \\
\text { IV. } 120000 \text { en adelante: cuota fija } \$ 223.89 \text { y tasa } 2.25 \text { al } \\
\text { millar sobre excedente del límite inf. (art. } 3 \text { ). }\end{array}$ \\
\hline Límite & - \\
\hline
\end{tabular}

Fuente: Leyes de Ingresos Municipales, http://congresocoahuila.gob.mx/portal/ejercicio -fiscal-2015

\section{Cuadro 7}

Marco normativo del impuesto predial de los municipios de Sonora, 2015

\begin{tabular}{|l|l|}
\hline Ley estatal & Ley de Hacienda Municipal del Edo. de Sonora. \\
\hline Base & $\begin{array}{l}\text { Predios urbanos y rurales, valor catastral; predios rústi- } \\
\text { cos, lo que resulte mayor entre valor catastral y comer- } \\
\text { cial (art. 55). }\end{array}$ \\
\hline
\end{tabular}




\section{Cuadro 7}

\section{(continúa)}

\begin{tabular}{|l|l|}
\hline Tarifa & $\begin{array}{l}\text { El impuesto se causará y pagará a la tasa, tarifa o cuota } \\
\text { que se fije en las leyes de ingresos de los ayuntamientos } \\
\text { (art. 55). Predios rústicos ejidales o comunales hasta en } \\
\text { tanto los ayuntamientos envíen propuesta de tasa o tarifa, } \\
\text { la tasa aplicable será de 3\% sobre el valor de la produc- } \\
\text { ción comercializada (art. 3 transitorio). }\end{array}$ \\
\hline Descuentos & $\begin{array}{l}\text { Jubilado o pensionado, o viuda de algunos de los suje- } \\
\text { tos anteriores, mayor de 65 años, discapacitado, 4 años o } \\
\text { más prestando servicios como socorrista de la Cruz Roja } \\
\text { Mexicana, o como bombero o voluntario, se aplicará el } \\
\text { crédito fiscal correspondiente reducido en 50\% (art. 53). } \\
\text { Los ayuntamientos entregarán 50\% del predial ejidal al } \\
\text { ejido o comunidad propietario o poseedor de los predios } \\
\text { donde se genere (art. 61 bis). }\end{array}$ \\
\hline
\end{tabular}

\section{Hermosillo}

\begin{tabular}{|l|l|}
\hline Ley municipal & $\begin{array}{l}\text { Ley de Ingresos y Presupuesto de Ingresos del H. Ayun- } \\
\text { tamiento del Mpio. de Hermosillo. }\end{array}$ \\
\hline $\begin{array}{l}\text { Contribuciones } \\
\text { extraordinarias }\end{array}$ & $\begin{array}{l}\text { En caso de aceptarlo, \$35 para Cruz Roja, becas para ni- } \\
\text { ños y Cuerpo de Bomberos (art. 10). }\end{array}$ \\
\hline Pronto pago & - \\
\hline Grupos vulnerables & - \\
\hline Actualización de valor & $\begin{array}{l}\text { Se reducirá el predial del ejercicio en los casos en que, } \\
\text { como consecuencia de la actualización de los valores ca- } \\
\text { tastrales, el importe resulte mayor a 10\% del causado en } \\
\text { el ejercicio anterior (art. 163). }\end{array}$ \\
\hline Sectores económicos & Se entregará 50\% del predial ejidal pagado (art. 15). \\
\hline Tarifa & $\begin{array}{l}\text { 9 al millar sobre valor catastral (art. 9). } \\
\text { Predios rústicos ejidales o comunales, tasa de 2\% de la } \\
\text { producción comercializada (art. 14). }\end{array}$ \\
\hline
\end{tabular}

\section{Cajeme}

\begin{tabular}{|l|l|}
\hline Ley municipal & $\begin{array}{l}\text { Ley de Ingresos y Presupuesto de Ingresos del Ayunta- } \\
\text { miento del Mpio. de Cajeme. }\end{array}$ \\
\hline $\begin{array}{l}\text { Contribuciones } \\
\text { extraordinarias }\end{array}$ & $\begin{array}{l}\text { Aportación voluntaria por \$15 para Cruz Roja, DIF y } \\
\text { Cuerpo de Bomberos (art. 10). }\end{array}$ \\
\hline Pronto pago & $\begin{array}{l}\text { 20\% en enero, 15\% feb. y en abr.; los contribuyentes ten- } \\
\text { drán derecho a la no causación de recargos sobre el pri- } \\
\text { mer trimestre (art. 10). }\end{array}$ \\
\hline Grupos vulnerables & - \\
\hline
\end{tabular}




\section{Cuadro 7}

\section{(continúa)}

\begin{tabular}{|l|l|}
\hline Actualización de valor & - \\
\hline Sectores económicos & $\begin{array}{l}\text { Se entregará 50\% al ejido o comunidad propietario o po- } \\
\text { seedor de los predios donde se genera el gravamen (art. } \\
\text { 18). Para fomentar actividades agrícolas, ganaderas, } \\
\text { acuícolas, mineras y turísticas, se establece tasa de 1.39 } \\
\text { al millar para cálculo del predial de 2015, con objetivo de } \\
\text { equilibrar condiciones con el sector urbano (art. 3 tran- } \\
\text { sitorio). Predios ejidales que se utilicen para producción } \\
\text { agropecuaria, silvícola o acuícola pagarán tasa de 2\% so- } \\
\text { bre el valor de la producción anual comercializada (art. } \\
\text { 17). Para predios rurales y los del programa de desarro- } \\
\text { llo de área urbana de Cd. Obregón, las comisarías de Es- } \\
\text { peranza, Cócorit y Providencia, siempre que se utilicen } \\
\text { para actividades agrícolas o ganaderas, el impuesto es la } \\
\text { tasa general de 0.51 al millar sobre el valor catastral de } \\
\text { los inmuebles (art. 9). }\end{array}$ \\
\hline Tarifa & $\begin{array}{l}\text { 1.345 al millar sobre valor catastral de los inmuebles (art. } \\
\text { 8). En ningún caso el predial será menor a un salario mí- } \\
\text { nimo vigente en Cajeme, ni excederá 3.5\% respecto al } \\
\text { cobro del año anterior (art. 14). }\end{array}$ \\
\hline
\end{tabular}

\section{Nogales}

\begin{tabular}{|l|l|}
\hline Ley municipal & $\begin{array}{l}\text { Ley de Ingresos y Presupuesto de Ingresos del Ayunta- } \\
\text { miento del Mpio. de la Heroica Nogales. }\end{array}$ \\
\hline $\begin{array}{l}\text { Contribuciones } \\
\text { extraordinarias }\end{array}$ & - \\
\hline Pronto pago & $\begin{array}{l}12 \% \text { en enero, } 5 \% \text { en feb. y 3\% en mzo. Si se paga por } \\
\text { internet, descuento de 12\% en enero, 8\% en feb. y 5\% en } \\
\text { mzo. (art. 13). }\end{array}$ \\
\hline Grupos vulnerables & $\begin{array}{l}\text { Jubilado o pensionado, viuda de jubilado o pensionado, } \\
\text { se aplicará reducción de 50\%. Edad superior a 65 años o } \\
\text { discapacitado, reducción de 50\% (art. 14). }\end{array}$ \\
\hline Actualización de valor & $\begin{array}{l}\text { Reducción en predial en casos en que, como consecuen- } \\
\text { cia de la actualización de los valores catastrales, el im- } \\
\text { porte resulte mayor a 10\% del causado en el ejercicio } \\
\text { anterior (art. 152). }\end{array}$ \\
\hline Sectores económicos & $\begin{array}{l}\text { Para apoyar a instituciones de asistencia privada sin fines } \\
\text { de lucro, se exentará del predial en 95\% (art. 3 transito- } \\
\text { rio). Para fomentar la construcción de estacionamientos } \\
\text { públicos, se puede exentar el impuesto predial (art. 16). }\end{array}$ \\
\hline
\end{tabular}




\section{Cuadro 7}

(concluye)

\begin{tabular}{|l|l|}
\hline Tarifa & $\begin{array}{l}1 \% \text { sobre el valor catastral (art. 7). Predios edificados, } \\
\text { tasa al valor catastral de } 1 \% \text {, menos el porcentaje del } \\
\text { subsidio de } 76.85 \% \text { (art. 8). Predios no edificados, tasa } \\
\text { del valor catastral de } 1 \% \text { menos el porcentaje del subsi- } \\
\text { dio de } 60.07 \% \text { (art. 9). En ningún caso el monto a pagar } \\
\text { será inf. a } 4.5630 \text { VSMDGV (art. 10). En predios rústi- } \\
\text { cos ejidales o comunales, la tasa aplicable será de } 2 \% \\
\text { sobre el valor de la producción comercializada (art. 19). }\end{array}$ \\
\hline
\end{tabular}

Fuente: Leyes de Ingresos Municipales, http:/www.boletinoficial.sonora.gob.mx/boletin/ publicaciones-anteriores.html

En el caso de Tamaulipas, el Código Municipal permite también a los municipios que determinen las tarifas del impuesto predial, $\mathrm{y}$ establece la posibilidad, que no la obligatoriedad, de que otorguen bonificaciones por pronto pago y descuentos a ciertos grupos vulnerables. En el Cuadro 8 aparecen las diferencias en los criterios que siguen los municipios de Reynosa, Victoria y Tampico para determinar el monto del impuesto predial.

Finalmente, para Baja California mostramos algunas de las reglas que se aplican para determinar el impuesto predial de Ensenada, Mexicali y Tijuana. En esta entidad, la Ley de Hacienda Municipal establece que la tasa del impuesto predial y los criterios para otorgar bonificaciones serán previstas en las leyes de ingresos municipales. Así, se pueden apreciar en el Cuadro 9 las diferencias en los descuentos por pronto pago, en las bonificaciones a grupos vulnerables, en los sectores económicos, y también en las tarifas para determinar el impuesto predial.

Es claro, entonces, lo que indicamos al inicio de esta sección, en el sentido de que la reforma constitucional del artículo 115 posibilita que las instituciones fiscales relacionadas con la recaudación del impuesto predial, tanto a escala estatal como municipal, sean diferentes para cada municipio mexicano. 


\section{Cuadro 8}

\section{Marco normativo del impuesto predial} de los municipios de Tamaulipas, 2015

\begin{tabular}{|l|l|}
\hline Ley estatal & Código Municipal para el Edo. de Tamaulipas. \\
\hline Base & Valor catastral (art. 107). \\
\hline Tarifa & $\begin{array}{l}\text { Los impuestos municipales se causarán en montos, tasas } \\
\text { y tarifas que al efecto señale la Ley de Ingresos Munici- } \\
\text { pales, y su regulación sustantiva en cuanto a objeto, suje- } \\
\text { to, base y monto del pago se determinará en los términos } \\
\text { de los siguientes artículos (art. 100). }\end{array}$ \\
\hline Exenciones & $\begin{array}{l}\text { Los bienes del dominio público de la federación, del edo. } \\
\text { y los mpios. están exentos (art. 123). }\end{array}$ \\
\hline Descuentos & $\begin{array}{l}\text { Los ayuntamientos pueden autorizar bonificación hasta } \\
\text { de } 15 \% \text { cuando los pagos se realicen en enero y feb.; has- } \\
\text { ta } 8 \% \text { en mzo. y abr. A jubilados, pensionados, quienes } \\
\text { tengan alguna discapacidad, adultos mayores de 60 años } \\
\text { o ejidatarios o campesinos, se puede autorizar bonifica- } \\
\text { ción de hasta 50\% (art. 109). }\end{array}$ \\
\hline
\end{tabular}

\section{Reynosa}

\begin{tabular}{|c|c|}
\hline Ley municipal & Ley de Ingresos del Mpio. de Reynosa. \\
\hline Pronto pago & $\begin{array}{l}15 \% \text { si paga en enero o feb., } 8 \% \text { si paga en mzo. y abr. } \\
\text { (art. 69). }\end{array}$ \\
\hline Grupos vulnerables & $\begin{array}{l}50 \% \text { a pensionados, jubilados y personas de } 60 \text { años o } \\
\text { más, incapacidad que impida trabajar (art. 68). }\end{array}$ \\
\hline Sectores económicos & $\begin{array}{l}50 \% \text { comodatos en favor del mpio., para actividades } \\
\text { deportivas, recreativas o culturales (art. 68). }\end{array}$ \\
\hline Tarifa & $\begin{array}{l}\text { I. Habitacional residencial, } 1.7 \text { al millar. } \\
\text { II. Comercio y oficinas, } 2.0 \text { al millar. } \\
\text { III. Dedicados al servicio de espectáculos y entreteni- } \\
\text { miento, } 2.0 \text { al millar. } \\
I V . \text { Hoteles, moteles y hospitales, } 2.0 \text { al millar. } \\
V . \quad \text { Escuelas, edificios u oficinas gubernamentales, } 2.0 \\
\text { al millar. } \\
\text { VI. Templos religiosos, } 0.5 \text { al millar. } \\
\text { VII. Predios urbanos sin edificaciones contiguos a bule- } \\
\text { vares y avs. principales, } 2.0 \text { al millar. } \\
\text { VIII. Industrial y otros, } 2.9 \text { al millar. } \\
I X . \text { Predios rústicos, } 1.5 \text { al millar. } \\
X . \quad \text { Casas hogar o predios con fines filantrópicos dedica- } \\
\\
\text { dos a atención de la orfandad, } 0.25 \text { al millar. }\end{array}$ \\
\hline
\end{tabular}




\section{Cuadro 8}

\section{(continúa)}

\begin{tabular}{|c|c|}
\hline Tarifa & $\begin{array}{l}\text { XI. Predios no edificados con destino de uso de suelo } \\
\text { habitacional residencial, el impuesto se causará au- } \\
\text { mentándolo en } 100 \% \text {; en todos los demás usos, cau- } \\
\text { sará de acuerdo a la tasa por destino de uso de suelo } \\
\text { señalada en este artículo. } \\
\text { XII. Tratándose de predios urbanos no edificados propie- } \\
\text { dad de fraccionamientos autorizados, no se aplicará } \\
\text { la tasa prevista en la fracción VI. } \\
\text { XIII. Los adquirientes de los lotes provenientes de frac- } \\
\text { cionamientos que no construyan en los predios en } \\
\text { un plazo de } 3 \text { años a partir de la contratación de } \\
\text { la operación, pagarán } 100 \% \text { más de impuesto, al } \\
\text { término de ese tiempo. } \\
X I V \text {. Los propietarios de fraccionamientos autorizados } \\
\text { pagarán } 100 \% \text { de aumento al impuesto por los pre- } \\
\text { dios no vendidos en un plazo de } 3 \text { años a partir de la } \\
\text { autorización oficial de la venta (art. 10). }\end{array}$ \\
\hline Límites & Cuota mínima de 3 SM (art. 67). \\
\hline
\end{tabular}

Victoria

\begin{tabular}{|c|c|}
\hline Ley municipal & Ley de Ingresos del Mpio. de Victoria. \\
\hline Pronto pago & $15 \%$ en enero o feb., $8 \%$ en mzo. y abr. (art. 56). \\
\hline Grupos vulnerables & $\begin{array}{l}50 \% \text { a pensionados, jubilados, personas de } 60 \text { años o más } \\
\text { y gente con discapacidad que les impida trabajar (art. 55). }\end{array}$ \\
\hline Sectores económicos & $\begin{array}{l}50 \% \text { comodatos en favor del mpio. para actividades de- } \\
\text { portivas, recreativas o culturales (art. 55). }\end{array}$ \\
\hline Tarifa & 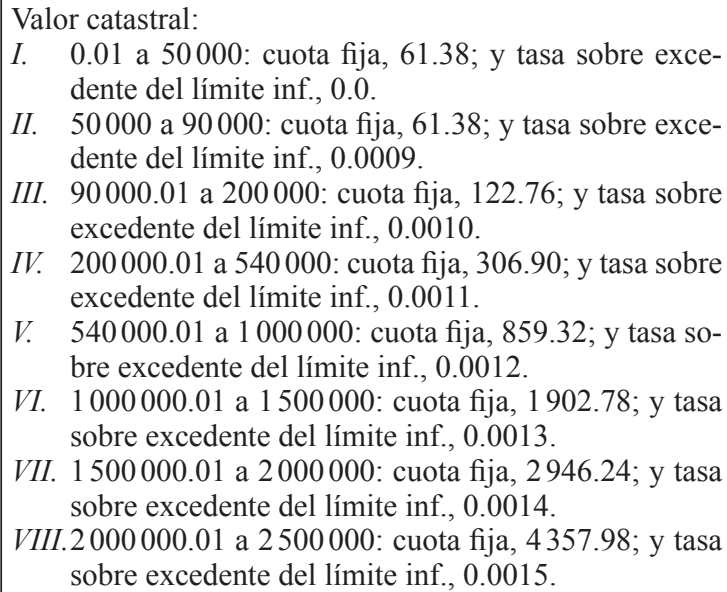 \\
\hline
\end{tabular}




\section{Cuadro 8}

(concluye)

\begin{tabular}{|l|l|}
\hline Tarifa & $\begin{array}{l}\text { IX. 2500 } 000.01 \text { en adelante: cuota fija 5 401.44 y tasa } \\
\text { sobre excedente del límite inf. 0.0016 (art. 10). } \\
1 \text { al millar anual sobre el valor catastral para predios rús- } \\
\text { ticos. (art. 10). }\end{array}$ \\
\hline Límites & Cuota mínima anual de 3 SM (art. 10). \\
\hline
\end{tabular}

Tampico

\begin{tabular}{|c|c|}
\hline Ley municipal & Ley de Ingresos del Mpio. de Tampico. \\
\hline Pronto pago & $\begin{array}{l}15 \% \text { si paga en enero, } 10 \% \text { en feb., } 7 \% \text { en mzo. y } 5 \% \text { en } \\
\text { abr. (art. } 69 \text { ). }\end{array}$ \\
\hline Grupos vulnerables & $\begin{array}{l}50 \% \text { a pensionados, jubilados o personas de } 60 \text { años o más } \\
\text { de edad; jefas de familia que sean madres en situación de } \\
\text { pobreza (solteras, separadas, divorciadas, viudas); perso- } \\
\text { nas con discapacidad que les impida laborar (art. 68). }\end{array}$ \\
\hline Sectores económicos & $\begin{array}{l}50 \% \text { comodatos en favor del mpio., para actividades de- } \\
\text { portivas, recreativas, culturales o altruistas (art. } 68 \text { ). }\end{array}$ \\
\hline Tarifa & 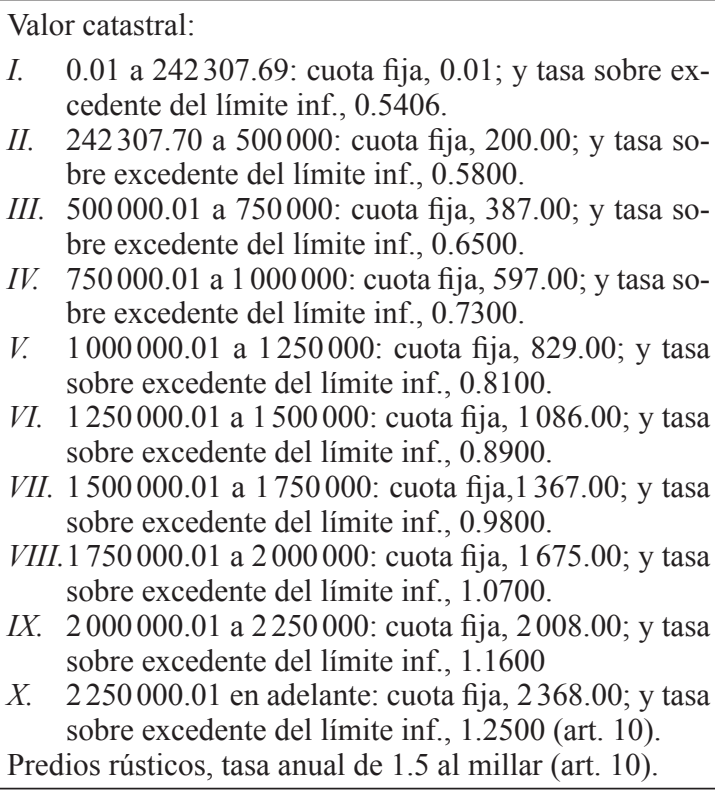 \\
\hline Límites & Cuota mínima anual de 3 SM (art. 11). \\
\hline
\end{tabular}

Fuente: Leyes de Ingresos Municipales, https://www.congresotamaulipas.gob.mx/ LegislacionEstatal/DisposicionesFiscales/LEYES\%20DE\%20INGRESOS\%20MUNICIPALES $\% 202015$.pdf 


\section{Cuadro 9}

Marco normativo del impuesto predial de los municipios de Baja California, 2015

\begin{tabular}{|l|l|}
\hline Ley estatal & $\begin{array}{l}\text { Ley de la Hacienda Municipal para el Edo. de Baja Ca- } \\
\text { lifornia. }\end{array}$ \\
\hline Base & $\begin{array}{l}\text { El valor catastral que resulte de la aplicación de la tabla } \\
\text { de valores catastrales unitarios, base del impuesto predial } \\
\text { autorizada para cada mpio., el cual deberá ser equipara- } \\
\text { ble al valor de mercado (art. 75 bis A). }\end{array}$ \\
\hline Tarifa & $\begin{array}{l}\text { La tasa del impuesto que corresponda pagar será la que } \\
\text { se determine en la Ley de Ingresos de cada mpio. del edo. } \\
\text { (art. 75 bis A). }\end{array}$ \\
\hline Descuentos & $\begin{array}{l}\text { Las leyes de ingresos municipales podrán prever el otor- } \\
\text { gamiento de estímulos a los contribuyentes del predial } \\
\text { que lo enteren oportunamente (art. 75 bis A). }\end{array}$ \\
\hline Exentos & $\begin{array}{l}\text { Los bienes inmuebles de dominio público propiedad de } \\
\text { la federación, del edo. o de los mpios., siempre y cuando } \\
\text { se usen para su objeto público (art. 75 bis A). }\end{array}$ \\
\hline
\end{tabular}

\section{Ensenada}

\begin{tabular}{|l|l|}
\hline Ley municipal & Ley de Ingresos del Mpio. de Ensenada. \\
\hline $\begin{array}{l}\text { Contribuciones } \\
\text { extraordinarias }\end{array}$ & - \\
\hline Pronto pago & $10 \%$ en enero, $8 \%$ en feb. y 7\% en mzo. (art. 3 bis). \\
\hline Grupos vulnerables & $\begin{array}{l}50 \% \text { (1.30 al millar) pensionados, jubilados, mayores de } \\
60 \text { años, siempre que el importe no sea menor a 1.5 veces } \\
\text { el SMDG. Discapacitados, quienes tengan a su cargo un } \\
\text { familiar con discapacidad, viudas mayores de 50 años y } \\
\text { jefas de familia de escasos recursos, lo que resulte menor } \\
\text { de 1.5 veces el SMDG y 2.6 al millar (art. 2). }\end{array}$ \\
\hline Baldíos / no edificados & $\begin{array}{l}\text { Zona turística, bajo régimen en propiedad en condomi- } \\
\text { nio y/o fideicomiso bancario: } 3.47 \text { al millar; empresa in- } \\
\text { dustrial: } 2.63 \text { al millar; comercio y de servicios: } 4.38 \text { al } \\
\text { millar; asociaciones de profesionistas sin fines de lucro: } \\
\text { 2.59 al millar; organizaciones, asociaciones o institucio- } \\
\text { nes de asistencia social privada con fines de interés pú- } \\
\text { blico, humanitarios y no como auxiliares de la asistencia } \\
\text { social privada: 3.00 veces SMDG; agrupaciones de pro- } \\
\text { ductores que realicen actividades agropecuarias y pes- } \\
\text { queras: } 3.00 \text { veces SMDG; instituciones de enseñanza: } \\
\text { 2.58 al millar (art. 2). }\end{array}$ \\
\hline
\end{tabular}




\section{Cuadro 9}

\section{(continúa)}

\begin{tabular}{|c|c|}
\hline Tarifa & 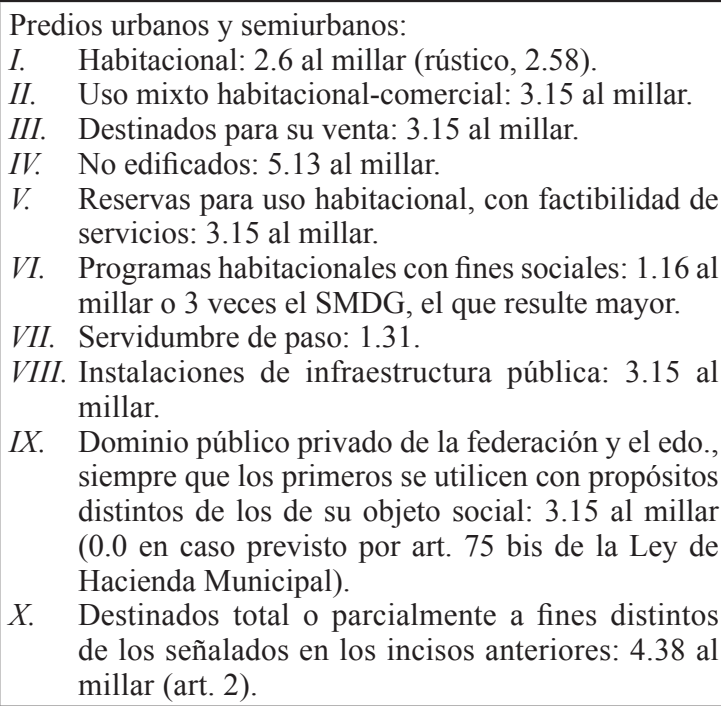 \\
\hline Límites & $\begin{array}{l}\text { El impuesto no podrá incrementarse en más de } 20 \% \text { res- } \\
\text { pecto al ejercicio anterior (art. } 3 \text { ). }\end{array}$ \\
\hline
\end{tabular}

\section{Mexicali}

\begin{tabular}{|l|l|}
\hline Ley municipal & Ley de Ingresos del Mpio. de Mexicali. \\
\hline $\begin{array}{l}\text { Contribuciones } \\
\text { extraordinarias }\end{array}$ & $\begin{array}{l}\text { Impuesto para fomento deportivo y educacional, 15\% so- } \\
\text { bre monto del impuesto (art. 5). }\end{array}$ \\
\hline Pronto pago & 20\% en enero, 15\% en feb. y 10\% en mzo. (art. 3 bis). \\
\hline Grupos vulnerables & $\begin{array}{l}50 \% \text { a pensionado, jubilado, discapacidad o mayor de } 60 \\
\text { años (art. 2). }\end{array}$ \\
\hline Baldíos / no edificados & $\begin{array}{l}50 \% \text { de descuento con Certificado de Mejoramiento de la } \\
\text { Imagen Urbana (art. 3 bis). }\end{array}$ \\
\hline Sectores económicos & $\begin{array}{l}\text { Asociaciones, sociedades u organizaciones de producto- } \\
\text { res agropecuarios o pesqueros: 3 veces SMDG; asociacio- } \\
\text { nes y sociedades asistenciales sin fines de lucro: 5 veces } \\
\text { SMDG; sociales, religiosos, educativos y organizaciones } \\
\text { sindicales: 6 al millar; dedicados permanentemente a fi- } \\
\text { nes agrícola, ganadero, forestal, acuícola, extracción de } \\
\text { pétreos, arenosos y cerril: 4 al millar (art. 2). }\end{array}$ \\
\hline
\end{tabular}




\section{Cuadro 9}

(concluye)

\begin{tabular}{|c|c|}
\hline Tarifa & $\begin{array}{l}\text { I. Baldíos y abandonados con construcciones: } 12 \text { al } \\
\text { millar. } \\
\text { II. Comerciales en plazas y corredores: } 8.75 \text { al millar. } \\
\text { III. Industriales: } 8.25 \text { al millar. } \\
\text { IV. Habitacionales: } 5 \text { al millar. } \\
\text { V. Agrupaciones debidamente constituidas: } 8 \text { al millar. } \\
\text { VI. Zonas habitacionales de uso industrial, comercial o } \\
\text { mixto: } 8.5 \text { al millar. } \\
\text { VII. Zonas urbanas de ejidos o poblados rurales en uso } \\
\text { habitacional: } 3.5 \text { al millar. } \\
\text { VIII. Reserva urbana o territorial: } 4 \text { al millar. }\end{array}$ \\
\hline Límites & No puede ser menor a 2 veces el SMDGV (art. 2). \\
\hline
\end{tabular}

Tijuana

\begin{tabular}{|l|l|}
\hline Ley municipal & Ley de Ingresos del Mpio. de Tijuana. \\
\hline $\begin{array}{l}\text { Contribuciones } \\
\text { extraordinarias }\end{array}$ & - \\
\hline Pronto pago & $7 \%$ en enero, 4\% en feb. y 2\% en mzo. (art. 7). \\
\hline Grupos vulnerables & - \\
\hline Baldíos /no edificados & $\begin{array}{l}\text { La tasa adicional sobre predios urbanos no edificados no } \\
\text { se aplica si el inmueble se destina a estacionamiento o } \\
\text { giro comercial (art. 4). }\end{array}$ \\
\hline Sectores económicos & $\begin{array}{l}\text { Tasa general aplicable a todos los predios es de 3.30 al } \\
\text { millar. Predios urbanos destinados a uso industrial causa- } \\
\text { rán impuesto adicionando 4.10 puntos al millar a la tasa } \\
\text { general. Predios urbanos no edificados o con construc- } \\
\text { ciones cuyo valor no llegue a 50\% del valor catastral del } \\
\text { terreno, causarán el impuesto adicionando 3. 70 puntos } \\
\text { al millar a la tasa general. Predios suburbanos, rústicos } \\
\text { o rurales causarán impuesto adicionando 3.70 puntos al } \\
\text { millar a la tasa general (art. 4). }\end{array}$ \\
\hline Límites & \begin{tabular}{l} 
No puede ser menor a 3 veces el SMDV (art. 5). \\
\hline
\end{tabular} \\
\hline
\end{tabular}

Fuente: Leyes de ingresos municipales, https://periodicooficial.ebajacalifornia.gob.mx/ oficial/inicio.jsp 


\section{Metodología}

El comportamiento de los ingresos municipales ha sido vinculado con variables económicas y demográficas (Kelsey, 1993; Buchanan y Weber, 1982; Henry y Lambert, 1980, entre otros), con las transferencias intergubernamentales (Bartle, 1995, 1996; Stine, 1985, 1994; Bell y Bowman, 1987), y en el área de economía política se consideran los aspectos políticos y las instituciones fiscales (Feld y Kirchgässner, 2001; Merrifield, 2000; Shadbegian, 1999; Alt y Lowry, 1994; Inman, 1979). Entre otros, hay dos aspectos políticos considerados en este estudio que se han relacionado con el desempeño fiscal de los gobiernos locales: la afiliación política de los gobernadores (Reed, 2006; Galli y Rossi, 2002; Feld y Kirchgässner, 2001; Nelson, 2000; Merrifield, 2000; Alt y Lowry, 1994; Blais y Nadeau, 1992) y los ciclos electorales (Galli y Rossi, 2002; Nelson, 2000; Blais y Nadeau, 1992). En particular, con respecto a la afiliación política (ideología), Alt y Lowry (1994) utilizan el modelo que denominan partidista (partisan model) para argumentar que las bases que apoyan a los partidos tienen diferentes preferencias, las cuales se reflejarían en las decisiones de los alcaldes; en nuestro caso, referentes al gasto de gobierno y al ingreso fiscal. Sólo para efectos de ilustración, la idea de que las variables relacionadas con los partidos políticos influyen en el nivel de los impuestos, es aplicada por Reed (2006) a los estados de Norteamérica, y por Allers, De Hann y Sterks (2001) a los municipios holandeses (estos últimos estudian cómo las diferencias en ideología influyen en la carga del impuesto predial). Para el caso de México, Díaz-Cayeros (2001) observa que los gobiernos encabezados por partidos diferentes al Partido Revolucionario Institucional (PRI) muestran una mayor recaudación de ingresos propios.

Teniendo en cuenta esta literatura sobre los determinantes de los ingresos locales y con base en los estudios de Ibarra Salazar y Sotres Cervantes $(2009 ; 2013 ; 2014 ; 2015)$, en este artículo relacionamos la recaudación del impuesto predial per cápita $(\mathrm{R})$ de los municipios ubicados en las entidades de la frontera norte con variables que aproximan la capacidad fiscal, la necesidad fiscal, las transferencias intergubernamentales, las diferencias institucio- 
nales, las variables políticas y la ubicación del municipio en la zona de la frontera norte.

Para aproximar la capacidad fiscal necesitamos una medida de ingreso municipal, pero dado que no existen estimaciones del producto interno bruto municipal, en este estudio lo estimamos usando la participación del municipio en la producción bruta estatal a partir de los Censos Económicos 2009 y 2014 (INEGI, 2009; 2014). Obtuvimos la participación para cada año del periodo 2008-2013 aplicando una tasa de crecimiento promedio anual a la participación de 2008; para los años de 2013 a 2015 asumimos que esta contribución se mantiene constante, para lo cual tomamos la participación obtenida de los Censos Económicos 2014. Este porcentaje se multiplicó por el producto interno bruto estatal de cada entidad para obtener la figura municipal, y posteriormente lo dividimos por la población para calcular el PIB municipal per cápita (PIBM).

Para medir la necesidad fiscal empleamos dos medidas demográficas: la población y la densidad de población (D).

La variable transferencias $(\mathrm{T})$ se refiere al monto per cápita que reciben los municipios por concepto de participaciones y aportaciones federales, excluyendo las transferencias estatales.

Las variables políticas se incorporaron a través de variables binarias que identifican el periodo del gobierno municipal (DPG) y la afiliación política del alcalde en turno (DPP).

Los municipios fronterizos se identifican con una variable binaria para todo el conjunto (DMF), y otra variable para los municipios fronterizos en cada uno de los estados (DF).

Por último, incluimos una variable dicotómica para incorporar el efecto del marco institucional propio del estado (DE). El Cuadro 10 presenta la descripción de las variables y las fuentes de información empleadas, y el Cuadro 11 muestra la estadística descriptiva de las variables consideradas en la estimación de los distintos modelos.

Para estimar el modelo empírico empleamos un panel de datos que combina información en corte transversal de los 225 municipios de las cinco entidades fronterizas, con series de tiempo anual para el periodo 2010-2015. 


\section{Cuadro 10}

Descripción de variables y fuentes de información

\begin{tabular}{|c|c|c|}
\hline Variable & Descripción & Fuente \\
\hline $\mathrm{R}$ & $\begin{array}{l}\text { Recaudación de impuesto predial per cápita (pesos } \\
\text { constantes de 2010). }\end{array}$ & INEGI, 2018a. \\
\hline PIBM & $\begin{array}{l}\text { PIB municipal per cápita (pesos constantes de } \\
\text { 2010). Se estimó multiplicando el PIB del edo. por } \\
\text { el porcentaje que representa la producción bruta } \\
\text { municipal respecto de la producción bruta estatal. } \\
\text { Después se dividió por la población total munici- } \\
\text { pal. }\end{array}$ & $\begin{array}{l}\text { PIB: INEGI, } \\
\text { 2018b. Pro- } \\
\text { ducción bruta: } \\
\text { INEGI, 2009; } \\
2014 \text {. }\end{array}$ \\
\hline $\mathrm{D}$ & $\begin{array}{l}\text { Densidad de población. Se calculó dividiendo la } \\
\text { población del mpio. por su extensión territorial } \\
\left(\text { habs. } / \mathrm{km}^{2}\right) \text {. Para los años intermedios se calculó } \\
\text { la tasa de crecimiento promedio anual. }\end{array}$ & $\begin{array}{l}\text { Población: } \\
\text { INEGI, 2010; } \\
\text { 2015. Extensión } \\
\text { territorial: Segob } \\
\text { e Inafed, 2011 }\end{array}$ \\
\hline $\mathrm{T}$ & $\begin{array}{l}\text { Ingresos por transferencias per cápita (pesos cons- } \\
\text { tantes de 2010). Incluye participaciones federales } \\
\text { netas (excluye las estatales) y aportaciones federa- } \\
\text { les del Ramo 33. }\end{array}$ & INEGI, 2018a. \\
\hline DPG & $\begin{array}{l}\text { Variable dicotómica para controlar por periodo de } \\
\text { gobierno municipal. Toma valor } 1 \text { en el } 2 \text { o periodo } \\
\text { de gobierno (entre 2010-2015) y } 0 \text { en otro caso. }\end{array}$ & $\begin{array}{l}\text { CIDAC, varios } \\
\text { años. }\end{array}$ \\
\hline DPP & $\begin{array}{l}\text { Variable dicotómica para controlar por la diferente } \\
\text { afiliación política del presidente municipal. Toma } \\
\text { valor } 1 \text { si el presidente es del PRI, y } 0 \text { en otro caso. }\end{array}$ & $\begin{array}{l}\text { CIDAC, varios } \\
\text { años, e institutos } \\
\text { electorales esta- } \\
\text { tales. }\end{array}$ \\
\hline DMF & $\begin{array}{l}\text { Variable dicotómica para incorporar la diferencia } \\
\text { en recaudación de predial del conjunto de mpios. } \\
\text { fronterizos. Toma valor } 1 \text { si el mpio. es fronterizo } \\
(36 \text { mpios. en total }) \text { y } 0 \text { en otro caso. }\end{array}$ & $\begin{array}{l}\text { Construcción } \\
\text { propia. }\end{array}$ \\
\hline $\mathrm{DMF}_{\mathrm{k}}$ & $\begin{array}{l}\text { Variable dicotómica para incorporar la diferencia } \\
\text { en recaudación de predial debido al marco insti- } \\
\text { tucional propio del mpio. fronterizo perteneciente } \\
\text { al edo. } k \text {. Toma valor } 1 \text { si el mpio. perteneciente al } \\
\text { edo. } k \text { es fronterizo, y } 0 \text { en otro caso. }\end{array}$ & $\begin{array}{l}\text { Construcción } \\
\text { propia. }\end{array}$ \\
\hline $\mathrm{DE}_{\mathrm{k}}$ & $\begin{array}{l}\text { Variable dicotómica para incorporar la diferencia } \\
\text { en recaudación de predial debido al marco institu- } \\
\text { cional propio del edo. } k \text {. Toma valor } 1 \text { si el mpio. } \\
\text { pertenece al edo. } k \text {, y } 0 \text { en otro caso. }\end{array}$ & $\begin{array}{l}\text { Construcción } \\
\text { propia. }\end{array}$ \\
\hline
\end{tabular}




\section{Cuadro 11}

Estadística descriptiva $(\mathrm{N}=1096)$

\begin{tabular}{|c|c|c|c|c|c|c|c|}
\hline & $R$ & PIBM & $D$ & $T$ & DMF & $D P G$ & $D P P$ \\
\hline Media & 141.4 & 76932.3 & 63.2 & 3783.4 & 0.15 & 0.46 & 0.61 \\
\hline Máximo & 1540.8 & 3385670.0 & 4617.0 & 16635.9 & 1.00 & 1.00 & 1.00 \\
\hline Mínimo & 3.0 & 102.4 & 0.21 & 271.9 & 0.00 & 0.00 & 0.00 \\
\hline SD & 139.0 & 273764.9 & 366.0 & 2654.7 & 0.36 & 0.50 & 0.49 \\
\hline \multicolumn{8}{|c|}{ Matriz de correlaciones } \\
\hline $\mathrm{R}$ & 1.000 & & & & & & \\
\hline PIBM & 0.285 & 1.000 & & & & & \\
\hline D & 0.033 & 0.075 & 1.000 & & & & \\
\hline $\mathrm{T}$ & -0.049 & -0.115 & -0.139 & 1.000 & & & \\
\hline $\mathrm{DMF}$ & 0.172 & -0.017 & 0.030 & -0.168 & 1.000 & & \\
\hline DPG & 0.045 & 0.039 & -0.037 & 0.104 & -0.014 & 1.000 & \\
\hline DPP & 0.009 & -0.028 & 0.073 & -0.082 & 0.010 & -0.137 & 1.000 \\
\hline
\end{tabular}

Fuente: Elaboración propia.

Estimamos el modelo restringido $(\mathrm{R})$ incluyendo solamente las variables de control. Éstas corresponden a nuestra aproximación del ingreso per cápita municipal (PIBM), la densidad de población (D), las variables políticas (DPG y DPP) y las transferencias (T):

$$
\mathrm{R}_{\mathrm{ikt}}=\alpha+\theta \mathrm{X}_{\mathrm{ikt}}+\varepsilon_{\mathrm{ikt}},
$$

donde $i$ representa el municipio (225), $k$ el estado fronterizo (5), $t$ el año (2010-2015), $\varepsilon$ representa el término del error, X es el vector que incluye las variables de control, y $\theta$ es el vector que incluye los parámetros de las variables de control.

Para determinar el efecto global de la frontera en la recaudación del impuesto predial proponemos dos especificaciones. El modelo 1 incluye una variable binaria (DMF) para identificar a los municipios fronterizos:

$$
\mathrm{R}_{\mathrm{ikt}}=\alpha+\beta \mathrm{DMF}+\theta \mathrm{X}_{\mathrm{ikt}}+\varepsilon_{\mathrm{itk}}
$$


El parámetro de la variable binaria $(\beta)$ representa la diferencia en la recaudación del predial entre los municipios fronterizos y los no fronterizos en los estados considerados en este estudio. En efecto, cuando se trata de un municipio fronterizo, la variable DMF adopta el valor de uno, con lo que el valor estimado de $\mathrm{R}_{\mathrm{ikt}}$ sería igual a $\alpha$ $+\beta+\theta \mathrm{X}_{\mathrm{ikt}}$. En el caso de municipios no fronterizos, cuando DMF es igual a cero, el valor estimado de $\mathrm{R}_{\mathrm{ikt}}$ es $\alpha+\theta \mathrm{X}_{\mathrm{ikt}}$. La diferencia entre ambos es el parámetro $\beta$. Dados los valores de las variables de control (X) y el valor de $\alpha$, si la recaudación del predial de un municipio fronterizo es mayor a la de otro no fronterizo, entonces se esperaría que $\beta$ fuera positiva. Ya que en [2] no identificamos el estado al que pertenecen los municipios, suponiendo que el término constante es igual para todos, el parámetro $\beta$ nos indica el efecto global de la frontera, sin controlar por las diferencias institucionales que puedan existir entre los estados considerados en este estudio.

En el modelo 2 relajamos esas restricciones. Estimamos los efectos de las diferencias que pueden existir en la recaudación del predial por los distintos marcos institucionales de los estados fronterizos. En efecto, el modelo 2 incorpora un término constante diferente para cada estado $\left(\alpha_{\mathrm{k}}\right)$ :

$$
\mathrm{R}_{\mathrm{ikt}}=\alpha_{\mathrm{k}}+\beta \mathrm{DMF}+\theta \mathrm{X}_{\mathrm{ikt}}+\varepsilon_{\mathrm{ikt}} .
$$

Con relación a los modelos de efectos fijos con datos del panel, de acuerdo con Greene (2008), Baltagi (2001) y particularmente Hsiao $\left(2003\right.$, p. 30), estas constantes $\left(\alpha_{\mathrm{k}}\right)$ representan los efectos de las características propias de cada estado $k$, que se omiten en el modelo y que son constantes en el tiempo. Dado que en la especificación [3] estamos controlando por las diferencias en capacidad y necesidad fiscal, el monto de transferencias recibido, así como por diferencias de tipo político entre los municipios, consideramos que el término constante captura el efecto sobre la recaudación del impuesto predial de las discrepancias institucionales ${ }^{7}$ que enfrentan los municipios en

${ }^{7}$ Stein, Talvi y Grisanti (1999) definen las instituciones fiscales como el conjunto de reglas y procedimientos de acuerdo a las que se elabora, aprueba e implementa el presupuesto gubernamental. Tipifican las instituciones fiscales con base 
los diferentes estados. Esto es así ya que, a pesar de enfrentar el mismo marco legal en el ámbito fiscal federal, los municipios en cada estado enfrentan un marco fiscal diferenciado de acuerdo a las leyes fiscales que se aprueban en las legislaturas locales, tal como argumentamos en la sección anterior (Cuadro 4).

De esta forma, el parámetro $\beta$ del modelo 2 captura la diferencia en la recaudación del predial entre los municipios fronterizos y los no fronterizos en cada entidad, suponiendo que esta diferencia es constante. Específicamente, incluyendo efectos fijos estatales, y controlando por las diferencias en las variables del vector X, el remanen$t^{8}$ de la recaudación estimada en cualquier municipio no fronterizo del estado $k$ sería igual a $\alpha_{k}$, mientras que el de cualquier municipio fronterizo del estado $k$ sería igual a $\alpha_{\mathrm{k}}+\beta$. Esto es así ya que, para cualquier municipio fronterizo, el valor de la variable DMF es igual a uno. Además, la diferencia entre $\alpha_{\mathrm{k}} \mathrm{y} \alpha_{\mathrm{j}}$, con $j \neq k$, representaría el contraste entre el remanente de la recaudación del predial de los municipios del estado $k$ en comparación con los del estado $j$. Así, al comparar $\alpha_{k}+\beta$ contra $\alpha_{j}$, tendremos la diferencia en recaudación entre los municipios fronterizos del estado $k \mathrm{y}$ los municipios no fronterizos del estado $j$.

Para determinar si los efectos fijos estatales ayudan a explicar las diferencias en la recaudación del predial, comparamos los modelos 1 y 2. Esto implica determinar la significancia de los efectos de grupo (Greene, 2008, p. 197). Si las características institucionales en los estados tienen un impacto en las variaciones en la recaudación del impuesto predial, entonces habría una diferencia significativa en la suma de los errores al cuadrado entre estos modelos. La hipóte-

en tres categorías. La primera se refiere a las reglas que fijan referencias numéricas con respecto a las variables fiscales. La segunda reúne las reglas procedimentales que gobiernan la elaboración, discusión y ejecución del presupuesto. La tercera alude a las asociadas con la transparencia del proceso presupuestal. Esto se refiere al grado en que el documento del presupuesto proporciona una representación real de los gastos, ingresos y déficits proyectados. Para ampliar la información sobre la importancia de las instituciones fiscales y la construcción de un índice de instituciones fiscales, véase von Hagen (1992) y von Hagen y Harden (1995); y para conocer la discusión de las instituciones fiscales, revísese Alesina y Perotti (1995).

${ }^{8}$ El remanente se refiere a la diferencia entre $\mathrm{R}_{\mathrm{ikt}} \mathrm{y} \theta \mathrm{X}_{\mathrm{ikt}}$ de la expresión [3]. 
sis nula para este caso es que los términos constantes en el modelo 2 sean iguales para todos los estados fronterizos $\left(\alpha_{\mathrm{BC}}=\alpha_{\mathrm{SON}}=\alpha_{\mathrm{CHIH}}\right.$ $\left.=\alpha_{\mathrm{COAH}}=\alpha_{\mathrm{TAM}}\right)$.

Los siguientes modelos abordan el efecto de los municipios fronterizos en cada uno de las entidades fronterizas. Partiendo del modelo 1 en [2], modificamos la variable dicotómica de los municipios fronterizos para incorporar cinco variables binarias que identifican a los municipios fronterizos en cada estado. En el modelo 3 se supone que los efectos estatales son iguales, lo que se refleja en el término constante $(\alpha)$ :

$$
\mathrm{R}_{\mathrm{ikt}}=\alpha+\beta_{\mathrm{k}} \mathrm{DMF}_{\mathrm{k}}+\theta \mathrm{X}_{\mathrm{ikt}}+\varepsilon_{\mathrm{ikt}} .
$$

El parámetro $\beta_{\mathrm{k}}$ representa la diferencia en recaudación del predial entre los municipios fronterizos del estado $k$ y el resto de los municipios considerados en el estudio, ya que en este modelo no se reconocen los efectos fijos estatales. El modelo 4, finalmente, incluye efectos estatales en el término constante $\left(\alpha_{k}\right)$, además de una variable binaria para cada grupo de municipios fronterizos en cada entidad:

$$
\mathrm{R}_{\mathrm{ikt}}=\alpha_{\mathrm{k}}+\beta_{\mathrm{k}} \mathrm{DMF}_{\mathrm{k}}+\theta \mathrm{X}_{\mathrm{ikt}}+\varepsilon_{\mathrm{ikt}}
$$

Si bien el parámetro $\beta_{\mathrm{k}}$ tiene el mismo significado que aquél en el modelo 2, en este caso se obtiene reconociendo que puede haber diferencias entre los municipios fronterizos de los diferentes estados. En particular, $\beta_{\mathrm{k}}$ es la diferencia en la recaudación del predial entre los municipios fronterizos y no fronterizos que pertenecen al estado $k$. La diferencia entre $\alpha_{\mathrm{k}} \mathrm{y} \alpha_{\mathrm{j}}$, con $j \neq k$ representa la diferencia de predial entre los municipios no fronterizos de los estados $k$ y $j$. Para determinar el monto en que difiere la recaudación entre municipios fronterizos de dos estados diferentes, $k$ y $j$, habría que calcular $\left(\alpha_{\mathrm{k}}+\right.$ $\left.\beta_{\mathrm{k}}\right)-\left(\alpha_{\mathrm{j}}+\beta_{\mathrm{j}}\right)$.

Dada la estrategia de inducción estadística que empleamos en este artículo, elegimos como método de estimación mínimos cuadrados ordinarios combinados (pooled regression) para los modelos 1 , 3 y 4 . Los modelos 2 y 5 fueron calculados empleando el enfoque 
de efectos fijos y el método de mínimos cuadrados con variables dicotómicas para los diferentes grupos (least squares dummy variable model) (Greene, 2008, pp.194-196).

\section{Resultados}

El Cuadro 12 presenta los resultados de las estimaciones. En cuanto a las variables de control incluidas, el producto interno bruto municipal (PIBM) muestra una relación positiva y significativa con la recaudación del predial per cápita $(\mathrm{R})$ en todos los modelos. Tomando como ejemplo los resultados del modelo 3 , el parámetro estimado que incorpora el efecto marginal de PIBM sobre $\mathrm{R}$ indica que, ceteris paribus, un incremento de un mil pesos en el PIBM provocará un aumento de 0.15 pesos en la recaudación per cápita del predial de los municipios.

\section{Cuadro 12}

Resultados de las estimaciones

$\begin{array}{ll}\text { Modelo } & \\ \text { Restringido } & \mathrm{R}_{\mathrm{ikt}}=\alpha+\theta \mathrm{X}_{\mathrm{ikt}}+\varepsilon_{\text {ikt }} \\ 1 & \mathrm{R}_{\mathrm{ikt}}=\alpha+\beta \mathrm{DMF}+\theta \mathrm{X}_{\mathrm{ikt}}+\varepsilon_{\mathrm{ikt}} \\ 2 & \mathrm{R}_{\mathrm{ikt}}=\alpha_{\mathrm{k}}+\beta \mathrm{DMF}+\theta \mathrm{X}_{\mathrm{ikt}}+\varepsilon_{\mathrm{ikt}} \\ 3 & \mathrm{R}_{\mathrm{ikt}}=\alpha+\beta_{\mathrm{k}} \mathrm{DMF}_{\mathrm{k}}+\theta \mathrm{X}_{\mathrm{ikt}}+\varepsilon_{\text {ikt }} \\ 4 & \mathrm{R}_{\mathrm{ikt}}=\alpha_{\mathrm{k}}+\beta_{\mathrm{k}} \mathrm{DMF}_{\mathrm{k}}+\theta \mathrm{X}_{\mathrm{ikt}}+\varepsilon_{\mathrm{ikt}}\end{array}$

\begin{tabular}{|c|c|c|c|c|c|}
\hline & \multicolumn{5}{|c|}{ Modelo } \\
\hline & Restringido & 1 & 2 & 3 & 4 \\
\hline Constante & $\begin{array}{l}125.20 \\
(8.26)^{*}\end{array}$ & $\begin{array}{l}108.19 \\
(7.36)^{*}\end{array}$ & & $\begin{array}{l}108.66 \\
(7.45)^{*}\end{array}$ & \\
\hline $\mathrm{PIBM}_{\mathrm{it}}$ & $\begin{array}{c}1.43 \mathrm{E}-04 \\
(2.12)^{*}\end{array}$ & $\begin{array}{c}1.46 \mathrm{E}-04 \\
(2.16)^{*}\end{array}$ & $\begin{array}{c}1.45 \mathrm{E}-04 \\
(2.31)^{*}\end{array}$ & $\begin{array}{c}1.46 \mathrm{E}-04 \\
(2.15)^{*}\end{array}$ & $\begin{array}{c}1.47 \mathrm{E}-04 \\
(2.33)^{*}\end{array}$ \\
\hline$D_{i t}$ & $\begin{array}{c}3.55 \mathrm{E}-03 \\
(0.31)\end{array}$ & $\begin{array}{c}2.91 \mathrm{E}-03 \\
(0.29)\end{array}$ & $\begin{array}{c}1.27 \mathrm{E}-02 \\
(1.52)\end{array}$ & $\begin{array}{c}2.63 \mathrm{E}-03 \\
(0.27)\end{array}$ & $\begin{array}{c}1.58 \mathrm{E}-02 \\
(1.99)^{*}\end{array}$ \\
\hline $\mathrm{T}_{\mathrm{it}}$ & $\begin{array}{c}-9.29 \mathrm{E}-04 \\
(-0.31)\end{array}$ & $\begin{array}{c}6.85 \mathrm{E}-04 \\
(0.25)\end{array}$ & $\begin{array}{c}1.78 \mathrm{E}-03 \\
(0.64)\end{array}$ & $\begin{array}{c}5.02 \mathrm{E}-04 \\
(0.19)\end{array}$ & $\begin{array}{c}2.28 \mathrm{E}-03 \\
(0.84)\end{array}$ \\
\hline $\mathrm{DMF}_{i t}$ & & $\begin{array}{l}69.24 \\
(2.97)^{*}\end{array}$ & $\begin{array}{l}69.51 \\
(2.87)^{*}\end{array}$ & & \\
\hline
\end{tabular}




\section{Cuadro 12}

(concluye)

\begin{tabular}{|c|c|c|c|c|c|}
\hline$\overline{\mathrm{DPG}_{\mathrm{it}}}$ & $\begin{array}{l}10.88 \\
(1.35)\end{array}$ & $\begin{array}{l}10.63 \\
(1.35)\end{array}$ & $\begin{array}{c}18.52 \\
(2.42)^{*}\end{array}$ & $\begin{array}{c}9.58 \\
(1.25)\end{array}$ & $\begin{array}{c}18.08 \\
(2.36)^{*}\end{array}$ \\
\hline $\mathrm{DPP}_{\text {it }}$ & $\begin{array}{c}5.65 \\
(0.50)\end{array}$ & $\begin{array}{c}5.94 \\
(0.53)\end{array}$ & $\begin{array}{c}-2.86 \\
(-0.27)\end{array}$ & $\begin{array}{c}7.18 \\
(0.61)\end{array}$ & $\begin{array}{c}-1.18 \\
(-0.11)\end{array}$ \\
\hline $\begin{array}{l}\text { 1. Baja } \\
\text { California }\end{array}$ & & & $\begin{array}{l}193.56 \\
(3.21)^{*}\end{array}$ & & $\begin{array}{l}277.95 \\
(3.01)^{*}\end{array}$ \\
\hline 2. Coahuila & & & $\begin{array}{l}145.17 \\
(7.31)^{*}\end{array}$ & & $\begin{array}{l}147.38 \\
(6.90)^{*}\end{array}$ \\
\hline 3. Chihuahua & & & $\begin{array}{l}127.36 \\
(7.82)^{*}\end{array}$ & & $\begin{array}{l}121.63 \\
(7.35)^{*}\end{array}$ \\
\hline 4. Sonora & & & $\begin{array}{c}86.10 \\
(4.07)^{*}\end{array}$ & & $\begin{array}{c}79.57 \\
(3.74)^{*}\end{array}$ \\
\hline 5. Tamaulipas & & & $\begin{array}{c}49.06 \\
(3.32)^{*}\end{array}$ & & $\begin{array}{c}46.72 \\
(3.31)^{*}\end{array}$ \\
\hline $\mathrm{DMF}_{\mathrm{BC}}$ & & & & $\begin{array}{c}82.74 \\
(3.86)^{*}\end{array}$ & $\begin{array}{l}-93.29 \\
(-0.95)\end{array}$ \\
\hline $\mathrm{DMF}_{\mathrm{COAH}}$ & & & & $\begin{array}{l}72.54 \\
(1.57)\end{array}$ & $\begin{array}{l}34.35 \\
(0.68)\end{array}$ \\
\hline $\mathrm{DMF}_{\text {СHIH }}$ & & & & $\begin{array}{l}113.43 \\
(3.43)^{*}\end{array}$ & $\begin{array}{l}94.00 \\
(2.79)^{*}\end{array}$ \\
\hline $\mathrm{DMF}_{\text {SON }}$ & & & & $\begin{array}{l}74.32 \\
(1.26)\end{array}$ & $\begin{array}{l}96.54 \\
(1.61)\end{array}$ \\
\hline $\mathrm{DMF}_{\text {TAMPS }}$ & & & & $\begin{array}{c}3.35 \\
(0.26) \\
\end{array}$ & $\begin{array}{c}63.06 \\
(5.43)^{*}\end{array}$ \\
\hline Adj $R^{2}$ & 0.0791 & 0.1097 & 0.1646 & 0.1171 & 0.1736 \\
\hline $\mathrm{N}$ & 1096 & 1096 & 1096 & 1096 & 1096 \\
\hline
\end{tabular}

* Significancia con p-valor $<0.05 ; * *$ significancia con $\mathrm{p}$-valor $<0.10$.

Nota: Estadístico $t$ entre paréntesis. Todos los modelos fueron estimados usando la corrección de errores Newey-West HAC Standard.

Fuente: Elaboración propia.

Con respecto a la variable demográfica, que aproxima la necesidad fiscal, realizamos un ejercicio de calibración para seleccionar la que arrojara mejores resultados, siendo la densidad de población (D) la variable elegida. Se espera que una mayor densidad de población impacte positivamente en los ingresos por predial de los municipios. Los resultados de los diferentes modelos estimados confirman esta 
relación esperada: D revela una relación positiva con $\mathrm{R}$, y es estadísticamente significativa en el modelo 4.

Por otra parte, el parámetro de la variable de transferencias (T) resulta con signo positivo, aunque no es estadísticamente significativo en ninguno de los modelos. Como comentamos arriba, el efecto de las transferencias en el ingreso municipal ha sido un tema que se ha tratado en estudios relacionados. En nuestro caso, sólo hemos considerado a los municipios de los estados fronterizos y tomamos en forma conjunta las participaciones y las aportaciones federales. Por tal motivo, éste lo consideramos un resultado parcial que merece ser analizado con más detalle.

Con respecto a las variables políticas consideradas, los parámetros de las variables binarias relacionadas con la afiliación política del alcalde (DPP) resultaron con un signo que no fue uniforme en los diferentes modelos, aunque también no fueron estadísticamente significativos. Por otro lado, la variable que identifica el periodo de gobierno (DPG) muestra evidencia, sobre todo en los modelos 2 y 4 , de que hubo diferencias significativas en la recaudación de predial en los periodos gubernamentales de los estados considerados.

El parámetro de la variable binaria que identifica a todos los municipios fronterizos de los estados fronterizos (DMF) resultó positivo y estadísticamente significativo en los dos modelos que la incluyen (1 y 2). Esto se puede verificar también con el estadístico de prueba que aparece en el Cuadro 13 (II. Efecto frontera norte global). Tal resultado indica que la ubicación fronteriza de los municipios ayuda a explicar las diferencias en la recaudación del predial entre aquéllos de los estados fronterizos. Vale la pena resaltar la consistencia en la magnitud del efecto marginal de la variable DMF en ambos modelos. En el modelo 1, que no incluye efectos fijos estatales, el estimado es de 69.24 pesos, mientras que en el modelo 2, que incluye efectos fijos estatales, el efecto fronterizo es de 69.51 pesos. Esta estimación indica que, comparado con los municipios no fronterizos de las entidades fronterizas, los municipios fronterizos observaron una recaudación per cápita mayor en 69 pesos. 


\section{Cuadro 13}

Estadísticos de prueba

Modelo restringido $\mathrm{R}_{\mathrm{ikt}}=\alpha+\theta \mathrm{X}_{\mathrm{ikt}}+\varepsilon_{\mathrm{ikt}}$

Modelo 1

Modelo 2

Modelo 3

Modelo 4

$\mathrm{R}_{\mathrm{ikt}}=\alpha+\beta \mathrm{DMF}+\theta \mathrm{X}_{\mathrm{ikt}}+\varepsilon_{\mathrm{ikt}}$

$\mathrm{R}_{\mathrm{ikt}}=\alpha_{\mathrm{k}}+\beta \mathrm{DMF}+\theta \mathrm{X}_{\mathrm{ikt}}+\varepsilon_{\mathrm{ikt}}$

$\mathrm{R}_{\mathrm{ikt}}=\alpha+\beta_{\mathrm{k}} \mathrm{DMF}_{\mathrm{k}}+\theta \mathrm{X}_{\mathrm{ikt}}+\varepsilon_{\mathrm{ikt}}$

$\mathrm{R}_{\mathrm{ikt}}=\alpha_{\mathrm{k}}+\beta_{\mathrm{k}} \mathrm{DMF}_{\mathrm{k}}+\theta \mathrm{X}_{\mathrm{ikt}}+\varepsilon_{\mathrm{ikt}}$

\section{Diferencias institucionales entre estados}

$\mathrm{H}_{0}: \alpha_{1}=\alpha_{2}=\alpha_{3}=\alpha_{4}=\alpha_{5}$

Estadístico F

(P-valor)

\begin{tabular}{cc} 
Modelo 2 & Modelo 4 \\
\hline 16.93 & 15.13 \\
$(0.0000)$ & $(0.0000)$
\end{tabular}

II. Efecto frontera norte global

$\mathrm{H}_{0}: \beta=0$

\begin{tabular}{lcc} 
& Modelo 1 & Modelo 2 \\
\cline { 2 - 3 } Estadístico F & 8.80 & 8.23 \\
(P-valor) & $(0.0031)$ & $(0.0042)$ \\
\hline
\end{tabular}

III. Efecto frontera norte por estado

$H_{0}: \beta_{1}=\beta_{2}=\beta_{3}=\beta_{4}=\beta_{5}$

\begin{tabular}{lcc} 
& Modelo 3 & Modelo 4 \\
\cline { 2 - 3 } Estadístico F & 5.62 & 0.99 \\
(P-valor) & $(0.0002)$ & $(0.4126)$
\end{tabular}

Fuente: Elaboración propia.

También podemos analizar el efecto frontera por entidad federativa. Los modelos 3 y 4 consideran tal efecto en los municipios a partir del estado al que pertenecen, incorporando de esta forma la idea de que la recaudación del predial puede variar al identificar la entidad de los municipios fronterizos. Para valorar este efecto, probamos si los parámetros $\beta_{\mathrm{k}}$ son iguales entre los estados. En el modelo 3 este parámetro captura la diferencia en la recaudación del predial entre los municipios fronterizos del estado $\mathrm{k}$ y el resto de los municipios considerados. El estadístico de prueba para el modelo 3 en el Cuadro 13 (III. Efecto frontera norte por estado) nos indica que debemos rechazar la hipótesis de que los efectos fronterizos estatales sean iguales. En particular, podemos apreciar en dicho cuadro que los efectos 
fronterizos de Baja California y Chihuahua son estadísticamente diferentes de cero. El valor estimado del primero es 82.74 pesos, y el del segundo es 113.43 pesos.

En el modelo 4 el parámetro $\beta_{\mathrm{k}}$ compara la recaudación de los municipios fronterizos del estado $\mathrm{k}$ con la de los municipios no fronterizos de esa misma entidad. El estadístico de prueba en el Cuadro 13 (III. Efecto frontera norte por estado) indica que no podemos rechazar la hipótesis de que estos parámetros sean iguales. Al incluir los efectos fijos estatales resultó que ahora los efectos fronterizos de Chihuahua y Tamaulipas son estadísticamente significativos. Nuestro estimado para el primer caso es de 94.00 pesos, y para el segundo, de 63.06 pesos.

Para determinar si las diferencias institucionales a escala estatal ayudan a explicar las diferencias en la recaudación del predial per cápita entre los municipios, usamos los modelos 2 y 4 , que incluyen efectos fijos estatales. Las contrapartes restringidas las constituyen los modelos 1 y 3 , respectivamente, que suponen una constante $(\alpha)$ uniforme entre los estados. Los estadísticos de prueba en el Cuadro 13 (I. Diferencias institucionales entre estados) indican que la hipótesis de efectos institucionales uniformes, tanto en el modelo 2 como en el 4, es rechazada. Esto aporta evidencia de que-controlando por la necesidad y capacidad fiscal, el monto de las transferencias federales y las variables políticas- las diferencias en la recaudación del predial per cápita de los municipios de los estados fronterizos son explicadas por las diferencias en sus instituciones fiscales. En nuestra perspectiva, esto se debe a que se ha modificado el marco institucional fiscal para incorporar la reforma constitucional de 1999 y a que los municipios puedan definir las reglas que les permitan aumentar la recaudación del impuesto predial.

\section{Conclusiones}

Con objeto de estimar y comparar el efecto frontera norte en la recaudación del predial, en este artículo hemos analizado los determinantes de dicha recaudación en los municipios de los estados de la región frontera norte de México. Estimamos diferentes especi- 
ficaciones usando un panel de datos anual (2010-2015) de los 225 municipios de Baja California, Sonora, Chihuahua, Coahuila y Tamaulipas. Las variables de control en nuestros modelos fueron: el ingreso municipal, la densidad de población, el monto de transferencias que reciben los municipios por parte del gobierno federal, y las variables políticas para reconocer la afiliación política del presidente municipal y el periodo de gobierno local.

Nuestro argumento, para el denominado efecto frontera norte, se ha fundamentado en las diferencias institucionales en el ámbito fiscal de los municipios en general, y de los fronterizos en particular. Al incorporar las diferencias institucionales en los modelos estimados, hemos argumentado que la definición de la base (tasa y tabla de valores) para determinar la recaudación de la fuente de ingreso propio más importante de los municipios, que es atribución municipal, es un elemento importante para explicar las diferencias en la recaudación del impuesto predial. Tal consideración es relevante ya que estamos frente a un instrumento de política fiscal local que, usado con la anuencia del congreso local, y de ser empleado apropiadamente por la autoridad municipal, puede ser una fuente de ingresos todavía más importante. Ello es precisamente lo que han confirmado los resultados de este artículo: que las diferencias institucionales son un factor importante para entender las variaciones en la recaudación del impuesto predial entre los municipios de los estados fronterizos.

En particular, los resultados en este estudio indican que la variable que identifica al grupo de municipios fronterizos (DMF) guarda una relación positiva y estadísticamente significativa con la recaudación del impuesto predial per cápita. Esto confirma nuestra hipótesis de que los municipios fronterizos obtienen una mayor recaudación del predial per cápita que el resto de los municipios de los estados fronterizos.

En este artículo hemos empleado los datos de los municipios de los estados fronterizos. Una extensión pudiera ser validar el efecto frontera norte usando datos de todos los municipios mexicanos, lo que haría posible comparar la recaudación del predial de los municipios fronterizos con aquellos de los estados no fronterizos. 


\section{Bibliografía}

Alesina, A. y Perotti, R. (1995). Fiscal expansions and adjustment in OECD countries. Economic Policy, 10(21), 205-248. https:// academic.oup.com/economicpolicy/article-abstract/10/21/205/ 2392283

Allers, M., De Hann, J. y Sterks, C. (2001). Partisan influence on the local tax burden in the Netherlands. Public Choice, 106(3-4), 351-363. https://link.springer.com/article/10.1023/A:100512320 8352

Alt, J. y Lowry, R. (1994). Divided government, fiscal institutions, and budget deficits: Evidence from the states. The American Political Science Review, 88(4), 811-828. https://www.jstor.org/stable/ 2082709 ?seq=1\#metadata_info_tab_contents

Arroyo, F. (2001). Dinámica del PIB de las entidades federativas de México, 1980-1999. Comercio Exterior, 51(7), 583-599. http:// revistas.bancomext.gob.mx/rce/magazines/34/1/RCE.pdf

Baltagi, B. (2001). Econometric analysis of panel data. Chichester: John Wiley and Sons.

Bartle, J. (1995). The fiscal impact of federal and state aid to large U.S. cities: An empirical analysis of budgetary response. $\mathrm{Pu}$ blic Budgeting and Finance, 15(4), 56-67. https://onlinelibrary. wiley.com/doi/abs/10.1111/1540-5850.01053

Bartle, J. (1996). The effect of intergovernmental aid on city property taxes: New results from Minnesota. Journal of Public Budgeting, Accounting and Financial Management, 8(2), 150-169. https:/www.emerald.com/insight/content/doi/10.1108/JPBA FM-08-02-1996-B001/full/html

Bell, M. y Bowman, J. (1987). The effect of various intergovernmental aid types on local own-source revenues: The case of property taxes in Minnesota cities. Public Finance Quarterly, 15(3), 282-297. https://journals.sagepub.com/doi/abs/10.1177/ 109114218701500303

Blais, A. y Nadeau, R. (1992). The electoral budget cycle. Public Choice,74(4),389-403.https://link.springer.com/article/10.1007/ BF00137686 
Broid Krauze, D. (2010). La evolución del predial en México: incentivos cruzados de la descentralización fiscal y política, 19902007. (Tesis de licenciatura, ITAM, Ciudad de México).

Buchanan, S. y Weber, B. (1982). Growth and residential property taxes: A model for estimating direct and indirect population impacts. Land Economics, 58(3), 324-337. https://www.jstor.org/ stable/3145940?seq=1\#metadata_info_tab_contents

Canavire-Bacarreza, G. y Espinoza, $\bar{N}$. (2015). Transferencias e impuesto predial en México. Economía UNAM, 12(35), 69-99. http:// www.revistas.unam.mx/index.php/ecu/article/view/51627/ 46098

Chiquiar, D. (2005). Why Mexico's regional income convergence broke down. Journal of Development Economics, 77(1), 257-275. https://www.sciencedirect.com/science/article/pii/S0304387 804001580?via\%3Dihub

CIDAC (Centro de Investigación para el Desarrollo A.C). (varios años). Base de datos electorales. Ciudad de México. http://cidac. org/

Deichmann, U., Lall, S., Redding, S. y Venables, A. (2008). Industrial location in developing countries. The World Bank Research Observer, 23(2), 219-246. https://elibrary.worldbank.org/doi/ abs/10.1093/wbro/lkn007

Díaz-Cayeros, A. (2001). Federalismo fiscal. En L. Rubio (coord.), Políticas económicas del México contemporáneo (pp. 187-219). Ciudad de México: Consejo Nacional para la Cultura y las Artes / Fondo de Cultura Económica.

Feld, L. y Kirchgässner, G. (2001). The political economy of direct legislation: Direct democracy and local decision-making. Economic Policy, 16(33), 329-367. Recuperado de http://www.jstor. org/stable/1344645

Galli,E. y Rossi, S. (2002). Political budget cycles: The case of the Western German Länder. Public Choice, 110(3-4), 283-303. https:// link.springer.com/article/10.1023\%2FA\%3A1013089504557

Greene, W. (2008). Econometric analysis. Nueva Jersey: Pearson-Prentice Hall.

Guillén, T. y Ziccardi, A. (coords.). (2004). Innovación y continuidad del municipio mexicano. Análisis de la reforma municipal 
de 13 estados de la república. Ciudad de México: UNAM, Instituto de Investigaciones Sociales / Miguel Ángel Porrúa.

Hanson, G. (2007). Globalization, labor income, and poverty in Mexico. En A. Harrison (ed.), Globalization and poverty (pp. 417-456). Chicago: University of Chicago Press / National Bureau of Economic Research.

Henry, M. y Lambert, K. (1980). The impact of new industry on county government property tax revenue. Southern Journal of Agricultural Economics, 12(1), 193-197. https://doi.org/10.1017/ S0081305200015478

Hsiao, C. (2003). Analysis of panel data. Cambridge: Cambridge University Press.

Ibarra Salazar, J. y Sotres Cervantes, L. (2009). Determinantes de la recaudación del impuesto predial en Tamaulipas: instituciones y zona frontera norte. Frontera Norte, 21(42), 165-192. http://www.scielo.org.mx/scielo.php?script=sci_arttext\&pid $=$ S0187-73722009000200007

Ibarra Salazar, J. y Sotres Cervantes, L. (2013). Las instituciones fiscales como paliativo para enfrentar crisis financieras: el impuesto predial en el estado de Coahuila. En J. E. Mendoza Cota (coord.), La crisis financiera internacional. Efectos sectoriales en México y en su frontera norte (pp. 315-353). Tijuana: El Colegio de la Frontera Norte.

Ibarra Salazar, J. y Sotres Cervantes, L. (2014). Diferencias en la recaudación de impuesto predial en la zona fronteriza: evidencia en los municipios de Chihuahua. Estudios Demográficos y Urbanos, 29(85), 53-87. https://estudiosdemograficosyurbanos. colmex.mx/index.php/edu/article/view/1455/1448

Ibarra Salazar, J. y Sotres Cervantes, L. (2015). Property tax collection of Sonora municipalities: Does border location make any difference? Journal of Borderlands Studies, 30(2), 203-225. https:// www.tandfonline.com/doi/full/10.1080/08865655.2015.1046471

Inman, R. (1979). Subsidies, regulations, and the taxation of property in large U.S. cities. National Tax Journal, 32(2), 159-168. Recuperado de https://www.jstor.org/stable/41863167?seq=1\#page_ scan_tab_contents 
INEGI (Instituto Nacional de Estadística y Geografía). (2000). XII Censo General de Población y Vivienda 2000. https://www. inegi.org.mx/programas/ccpv/2000/

INEGI (Instituto Nacional de Estadística y Geografía). (2004). Censos Económicos 2004. https://www.inegi.org.mx/programas/ce/ 2004/

INEGI (Instituto Nacional de Estadística y Geografía). (2009). Censos Económicos 2009. https://www.inegi.org.mx/programas/ce/ 2009/

INEGI (Instituto Nacional de Estadística y Geografía). (2010). Censo General de Población y Vivienda 2010. https://www.inegi. org.mx/programas/ccpv/2010/

INEGI (Instituto Nacional de Estadística y Geografía). (2014). Censos Económicos 2014. https://www.inegi.org.mx/programas/ ce/2014/

INEGI (Instituto Nacional de Estadística y Geografía). (2015). Encuesta Intercensal 2015. https://www.inegi.org.mx/programas/ intercensal/2015/

INEGI (Instituto Nacional de Estadística y Geografía). (2017). Estadística integral del Programa de la Industria Manufacturera, Maquiladora y de Servicios de Exportación (IMMEX). Banco de Información Económica (BIE). www.inegi.org.mx

INEGI(Instituto Nacional de Estadística y Geografía). (2018a). Finanzas públicas municipales. Consulta Interactiva de Datos. https:// www.inegi.org.mx/rnm/index.php/catalog/505

INEGI (Instituto Nacional de Estadística y Geografía). (2018b) Producto interno bruto por entidad federativa. Banco de Información Económica (BIE). www.inegi.org.mx

Kelsey, T. (1993). Fiscal impacts of population growth and decline in small communities. American Journal of Agricultural Economics, 75(5), 1169-1172. https://academic.oup.com/ajae/articleabstract/75/5/1169/121649? redirectedFrom=fulltext

Mendoza, E. (2001). Specialization, agglomeration and urban manufacturing growth in the northern border cities of Mexico. Journal of Borderlands Studies, 16(2), 71-97. https://www.tandfonline. com/doi/abs/10.1080/08865655.2001.9695575 
Mendoza, E. (2005). El TLCAN y la integración económica de la frontera México-Estados Unidos: situación presente y estrategias para el futuro. Foro Internacional, 45(3), 517-544.

Merrifield, J. (2000). State government expenditure determinants and tax revenue determinants revisited. Public Choice, 102(1-2), 25-50. https://www.jstor.org/stable/30026135?seq=1\#metadata_ info_tab_contents

Nelson, M. (2000). Electoral cycles and the politics of state tax policy. Public Finance Review, 28(6), 540-560. https://journals. sagepub.com/doi/abs/10.1177/109114210002800603

OCDE (Organización para la Cooperación y el Desarrollo Económicos). (2015). Estadísticas tributarias. www.oecd.org/centrode mexico/estadisticas

Reed, W. (2006). Democrats, republicans, and taxes: Evidence that political parties matter. Journal of Public Economics, 90(4-5), 725-750. https://www.sciencedirect.com/science/article/pii/S00 47272705000289

Ruelas Ávila, I. (2015). Evaluación de las características del impuesto predial en México. Revista Iberoamericana de Estudios $\mathrm{Mu}$ nicipales, 6(12), 67-102. http://revistariem.cl/index.php/riem/ article/view/45/29

Santana, S. (2000). Acciones necesarias para la implementación de la reciente reforma al artículo 115 constitucional: aspectos hacendarios. Hacienda Municipal, 72, 15-22.

Santana, S. y Sedas, C. (1999). El artículo 115 constitucional y sus reformas: comentarios a los aspectos hacendarios de la reforma de 1999. Hacienda Municipal, 68, 21-35.

Segob e Inafed (Secretaría de Gobernación e Instituto Nacional para el Federalismo y el Desarrollo Municipal). (2011). Enciclopedia de los municipios de México. Ciudad de México: Sistemas de Información Municipal.

Shadbegian, R. (1999). The effect of tax and expenditure limitations on the revenue structure of local government, 1962-87. National Tax Journal, 52(2), 221-237. https://www.jstor.org/stable/ 41789391?seq=1\#page_scan_tab_contents

Sour, L. (2004). El sistema de transferencias federales en México: ¿premio o castigo para el esfuerzo fiscal de los gobiernos locales 
urbanos? Gestión y Política Pública, 13(3), 733-753. http://hdl. handle.net/11651/1822

Sour, L. (2008). Un repaso de los conceptos sobre capacidad y esfuerzo fiscal, y su aplicación en los gobiernos locales mexicanos. Estudios Demográficos y Urbanos, 23(2), 271-297. https:// estudiosdemograficosyurbanos.colmex.mx/index.php/edu/ article/view/1312/1305

Stein, E., Talvi, E. y Grisanti, A. (1999). Institutional arrangements and fiscal performance: The Latin American experience. En J. Poterba y J. Von Hagen, (eds.), Fiscal institutions and fiscal performance (pp. 103-133). Chicago: Chicago University Press / NBER.

Stine, W. (1985). Estimating the responsiveness of local revenue to intergovernmental aid. National Tax Journal, 38(2), 227-234. https://www.jstor.org/stable/41792012

Stine, W. (1994). Is local government revenue response to federal aid symmetrical? Evidence from Pennsylvania county governments in an era of retrenchment. National Tax Journal, 47(4), 799-816. https://www.jstor.org/stable/41789109

Unda Gutiérrez, M. (2018). Los límites de la recaudación predial en los municipios urbanos de México: un estudio de casos. Estudios Demográficos y Urbanos, 33(3), 601-637. https://estudiosdemo graficosyurbanos.colmex.mx/index.php/edu/article/view/1741/ pdf

Unda Gutiérrez, M. y Moreno Jaimes, C. (2015). La recaudación del impuesto predial en México: un análisis de sus determinantes económicos en el período 1969-2010. Revista Mexicana de Ciencias Políticas y Sociales, 60(225), 45-78. http://www.revistas. unam.mx/index.php/rmcpys/article/view/51788

Von Hagen, J. (1992). Budgeting procedures and fiscal performance in the European communities. (Work Document, Economic Paper, 96). Bruselas, Bélgica: Commission of the European Communities for Economic and Financial Affairs. http://aei.pitt. edu/37058/1/A3038.pdf

Von Hagen, J. y Harden, I. (1995). Budget processes and commitment to fiscal discipline. European Economic Review, 39(3-4), 
771-779. Recuperado de https://www.sciencedirect.com/science/ article/pii/001429219400084D

\section{Leyes y ordenamientos legales}

Código Financiero para los Municipios del Estado de Coahuila de Zaragoza

Código Municipal para el Estado de Chihuahua

Código Municipal para el Estado de Tamaulipas

Constitución Política de los Estados Unidos Mexicanos

Decreto que Establece los Factores de Distribución de Participaciones

Federales a los Municipios del Estado de Sonora

Ley Catastral y Registral del Estado de Sonora

Ley de Catastro del Estado de Chihuahua

Ley de Catastro para el Estado de Tamaulipas

Ley de Coordinación Fiscal del Estado de Baja California

Ley de Coordinación Fiscal del Estado de Tamaulipas

Ley de Hacienda Municipal del Estado de Baja California

Ley de Hacienda Municipal del Estado de Sonora

Ley del Catastro Inmobiliario del Estado de Baja California

Ley General del Catastro y la Información Territorial para el Estado de Coahuila de Zaragoza

Ley para la Distribución de Participaciones y Aportaciones Federales

a los Municipios del Estado de Coahuila de Zaragoza

Leyes de Ingresos de cada municipio del Estado de Baja California

Leyes de Ingresos de cada municipio del Estado de Chihuahua

Leyes de Ingresos de cada municipio del Estado de Coahuila

Leyes de Ingresos de cada municipio del Estado de Sonora

Leyes de Ingresos de cada municipio del Estado de Tamaulipas

\section{Acerca de los autores}

Jorge Ibarra Salazar es doctor en Economía por la Southern Methodist University. Pertenece al Sistema Nacional de Investigadores, nivel II. Se desempeña como profesor investigador en el Departa- 
mento de Economía del Tecnológico de Monterrey, y como profesor visitante de la Southern Methodist University. Sus líneas de investigación son: finanzas públicas subnacionales, desempeño gubernamental, microeconomía aplicada y modelos de la firma en presencia de riesgo. ORCID: https://orcid.org/0000-0002-9581-9099

Entre sus publicaciones más recientes se encuentran:

Ibarra Salazar, J. (2019). Teoría económica del consumidor. Monterrey: Peart.

Ibarra Salazar, J., De la Fuente Pérez, D. y Miravete Martínez, M. (2021). La incidencia del impuesto especial sobre producción y servicios al tabaco en México. Contaduría y Administración, 66(1). http://www.cya.unam.mx/index.php/cya/article/ view $/ 2385 / 0$

Ibarra Salazar, J. (2020). La percepción de los funcionarios municipales sobre la reforma de 2014 al Fondo de Aportaciones para la Infraestructura Social. Espiral, Estudios de Estado y Sociedad, 28(78-79), 117-163. https://doi.org/10.32870/eees.v28i78-79

Lida Sotres Cervantes estudió la maestría en Negocios Internacionales para Latinoamérica, impartida por el Instituto Tecnológico y de Estudios Superiores de Monterrey (ITESM), campus Monterrey, México, y Thunderbird, The American Graduate School of International Management, Phoenix, AZ, Estados Unidos. Es licenciada en Economía por el ITESM. Sus áreas de investigación son: finanzas públicas, microeconomía aplicada y economía regional. Ha realizado estudios y proyectos de investigación en el marco de la Cátedra de Investigación Desarrollo Económico y Social, así como en el Centro de Estudios Estratégicos del ITESM. Ha participado en diferentes proyectos de consultoría en el sector privado y en el público, y ha realizado peritajes en materia económica.

Entre sus publicaciones se encuentran:

Ibarra Salazar, J. y Sotres Cervantes, L. (2015). Property tax collection of Sonora municipalities: Does border location make any difference? Journal of Borderlands Studies, 30(2), 203-225. http://dx.doi.org/10.1080/08865655.2015.1046471

Ibarra Salazar, J. y Sotres Cervantes, L. (2014). Diferencias en la recaudación de impuesto predial en la zona fronteriza: evidencia 
en los municipios de Chihuahua. Estudios Demográficos y Urbanos, 29(1), 53-87. http://dx.doi.org/10.24201/edu.v29i1.1455 Ibarra Salazar, J. y Sotres Cervantes, L. (2013). Las instituciones fiscales como paliativo para enfrentar crisis financieras: el impuesto predial en el estado de Coahuila. En J. E. Mendoza Cota (coord.). La crisis financiera internacional. Efectos sectoriales en México y en su frontera norte. Tijuana BC: El Colegio de la Frontera Norte.

Recepción: 19 de octubre de 2018. Aceptación: 23 de agosto de 2019. 
